\title{
Joint radio and optical observations of the most radio-powerful intracloud lightning discharges
}

\author{
A. R. Jacobson ${ }^{1}$, T. E. L. Light ${ }^{2}$, T. Hamlin ${ }^{2}$, and R. Nemzek ${ }^{2}$ \\ ${ }^{1}$ Earth and Space Sciences, University of Washington, Washington, USA \\ ${ }^{2}$ ISR-2, Los Alamos National Laboratory, Los Alamos, USA
}

Correspondence to: A. R. Jacobson (abramj@u.washington.edu)

Received: 12 December 2012 - Revised: 1 March 2013 - Accepted: 5 March 2013 - Published: 21 March 2013

\begin{abstract}
The most radio-powerful intracloud lightning emissions are associated with a phenomenon variously called "narrow bipolar events" or "compact intracloud discharges". This article examines in detail the coincidence and timing relationship between, on the one hand, the most radio-powerful intracloud lightning events and, on the other hand, optical outputs (or lack thereof) of the same discharge process. This is done, first, using coordinated very high frequency (VHF) and optical observations from the FORTE satellite and, second, using coordinated sferic and all-sky optical observations from the Los Alamos Sferic Array. In both cases, it is found that the sought coincidences are exceedingly rare. Moreover, in the handful of coincidences between optical and intense radio emissions that have been identified, the radio emissions differ from their usual behavior, by being accompanied by approximately simultaneous "conventional" lightning radio emissions. It is implied that the most radio-powerful intracloud emission process essentially differs from ordinary incandescent lightning.
\end{abstract}

Keywords. Meteorology and atmospheric dynamics (Atmospheric electricity; Lightning)

\section{Introduction}

Ordinary lightning involves a luminous, thermalized, incandescently heated channel (Gallimberti et al., 2002); indeed, "luminous" is implicit in the word "lightning". One type of lightning discharge in the upper portion of thunderstorms, however, appears less luminous than ordinary lightning; that is, it appears to be subthreshold for detection by satellite-borne optical detectors employed so far (Jacobson, 2003b; Jacobson and Heavner, 2005; Light and Jacobson,
2002). Why one distinctive type of thunderstorm electrical discharge would be relatively light-deficient is an outstanding puzzle and challenge of lightning physics. If a type of "lightning" can be relatively "dark", this has implications for the basic discharge physics. In this article we analyze a large quantity of archival satellite data and ground-array data of joint radio-optical lightning observations, to constrain further the assertion that a type of lightning can be light-deficient.

Two research satellites have carried radio receiver payloads for studying the very high frequency (VHF; 30$300 \mathrm{Mhz}$ ) emissions from lightning discharges. One of these satellites was Alexis (Holden et al., 1995; Massey and Holden, 1995; Massey et al., 1998), launched in 1993, while the other was Fast On-orbit Recording of Transient Events, or FORTE (Jacobson et al., 1999), launched in 1997. FORTE also carried optical payloads for lightning studies (Kirkland et al., 2001; Suszcynsky et al., 2000, 2001).

Satellite-borne VHF receivers, autonomously triggered on their own rising broadband signal from lightning, are biased toward seeing the most-intense VHF impulses. The mostintense radio impulses originate at cloud height, and hence are designated "intracloud" (IC). Often from a satellite, two pulses are recorded (Holden et al., 1995), though from the ground only one pulse is seen (Le Vine, 1980). Pairs of radio impulses seen from orbit have been named "transionospheric pulse pairs", or TIPPs, after the pioneering observations with the Blackbeard payload (Holden et al., 1995; Massey and Holden, 1995; Massey et al., 1998). The second pulse in a TIPP is due to a ground reflection, arriving with a relative delay at the satellite (relative to the first pulse). The delay is due to the additional propagation pathlength involved in reflecting from the ground. During the remainder 
of this paper, for brevity we refer to IC VHF impulses seen from orbit merely as "TIPPs", although the underlying radio emission is a single-pulse, not a double-pulse, physical emission. Although some authors have used "TIPP" to imply intense radio emitters, that is not intended here. The designation "TIPP" in the current work designates any pair of pulses for which the second is a ground reflection, but there is no restriction to intense emitters.

It has long been appreciated that very strong VHF TIPPs are frequently associated with the unique lightning stroke that is sometimes called a "narrow bipolar event", or NBE (Smith et al., 1999b). Another name employed for this unique stroke is "compact intracloud discharge", or CID (see, e.g., Nag et al., 2010). NBEs, and their accompanying VHF pulse, were originally reported in 1980 (Le Vine, 1980) and have been observed by many workers since (e.g., Eack, 2004; Hamlin et al., 2007; Holden et al., 1995; Jacobson, 2003a, b; Jacobson and Light, 2003, 2012; Jacobson and Heavner, 2005; Jacobson et al., 2007, 2011; Massey and Holden, 1995; Massey et al., 1998; Nag and Rakov, 2009, 2010a, b; Nag et al., 2010; Rison et al., 1999; Smith et al., 1999b; Thomas et al., 2001; Watson and Marshall, 2007; Wu et al., 2011, 2012).

Despite various efforts to detect light from very strong TIPPs, they appear (ca. 2012) to emit much less light than do ordinary lightning discharges emitting strong VHF (Jacobson, 2003a; Light and Jacobson, 2002). Similarly, NBE strokes detected by a ground-based lightning-location array have not been detectable optically from space even when they were in view of an operating satellite-borne optical photometer (Jacobson and Light, 2012). These assertions are of course subject to the detection threshold of the photometer, discussed in detail elsewhere (Jacobson and Light, 2012; Kirkland et al., 2001). Nonetheless, despite this caveat, the relatively "dark" behavior of NBEs, and the associated very intense TIPPs, remains a troubling enigma in lightning science.

The attempts cited above to check for an association either of TIPPs with light emission or of NBEs with light emission all involved autonomous triggering of the radio receiver off of impulsive rises in its own signal amplitude. In essence that approach poses the question, In the presence of radio emissions, what is the accompanying optical emission?

A different approach would be to use the optical photometer as the "master" signal, furnishing its own trigger but also commanding the VHF recording. This second approach poses the opposite question, In the presence of optical emissions, what is the accompanying VHF radio emission? This approach was begun (Light et al., 2001a) in a case study of 222 long (8.74 ms duration) VHF electric field recordings from FORTE. Each recording was triggered by a transient rise in the optical irradiance, which was in turn recorded with a long $(6.85 \mathrm{~ms})$ duration. Each radio-optical pair of concurrent records was examined, and the probable discharge type was inferred by the behavior of the radio-signal envelope. VHF envelope signatures can be used to discriminate be- tween various discharge types. This had been demonstrated by a detailed study (Suszcynsky et al., 2000) of radio-signal envelopes for discharges that had National Lightning Detection Network (NLDN; Cummins et al., 1998; Cummins and Murphy, 2009) ground-truth of the discharge type. On the basis of this NLDN "training", the radio envelope could, with significant reliability, identify when the VHF record accompanied a stroke of the following types: initial negative cloudto-ground $(-\mathrm{CG})$, subsequent $-\mathrm{CG}$, and positive cloud-toground $(+\mathrm{CG})$. In addition, pulse pairs were indicative of IC discharges (Massey and Holden, 1995; Massey et al., 1998), and during mixed sequences of pulse pairs and slower features the slower features could often be identified as intracloud K-processes (Shao and Krehbiel, 1996).

The 222-record study (Light et al., 2001a) served as an instructive case study, but the relatively small data set did not permit compelling statistical results regarding the occurrence of the unusual, very intense unpolarized TIPPs that are associated with NBEs (Jacobson and Light, 2003). The present paper takes the same approach of using optically controlled VHF recordings, so that the VHF features which are collected are not biased by their own need to trigger at some threshold. We extend the data set to tens of thousands of optically controlled VHF recordings. This is too many to analyze "by eye", and instead we use automated methods to perform very simple tests of the time relationship between optical and VHF signals, in different classes of VHF effective radiated Power (ERP). Then, when we have identified (a very small number of) powerful TIPPs that are found in optically controlled VHF records, we focus on a case study of those few individual recordings. Finally, we examine autonomously triggered VHF records which are coincident with autonomously triggered optical records, and find the same basic pattern of (a) temporal relationship between strong TIPPs and light output, and (b) details of the VHF envelope during the rare cases of optical coincidence.

\section{Instruments for this study}

\subsection{General}

This study uses data from instruments aboard the FORTE satellite, launched in August 1997 into a circular orbit (altitude $\sim 825 \mathrm{~km}$ ) with 70-degree inclination (Jacobson et al., 1999). The satellite carried four principal scientific instruments and had ample on-board memory. Stored records were downloaded to the ground station in Fairbanks, Alaska, several times a day. Two of the payloads were radio receivers, each of which was connected to one or the other of two crossed-polarization, $10 \mathrm{~m}$-long log-periodic antennas (Jacobson and Shao, 2002; Shao and Jacobson, 2001) directed along nadir. The other two payloads' instruments were optical detectors. All four payloads' basic parameters are summarized in Table 1. 
Table 1. FORTE instrument characteristics for this study.

\begin{tabular}{|c|c|c|c|c|}
\hline Instrument & TATR & HUMR & PDD & LLS \\
\hline Type & 2-band VHF receiver & 1-band VHF receiver & $\begin{array}{l}\text { Si photodiode pho- } \\
\text { tometer }\end{array}$ & CCD optical imager \\
\hline Field of view & $\begin{array}{l}\text { From nadir to Earth } \\
\text { limb, } 10 \mathrm{~m} \text { LPAs }\end{array}$ & $\begin{array}{l}\text { From nadir to Earth } \\
\text { limb, } 10 \mathrm{~m} \text { LPA }\end{array}$ & $\begin{array}{l}600 \mathrm{~km} \text {-radius cir- } \\
\text { cular FOV, nadir- } \\
\text { centered }\end{array}$ & $\begin{array}{l}1200 \times 1200 \mathrm{~km} \\
\text { square FOV, nadir- } \\
\text { centered }\end{array}$ \\
\hline Passband & $26-49 \mathrm{MHz}$ & $\begin{array}{l}\text { Ionospheric cutoff to } \\
85 \mathrm{MHz}\end{array}$ & $\begin{array}{l}\text { Si broadband } 0.4-1.1 \\
\text { micron }\end{array}$ & $777.6 \pm 0.55 \mathrm{~nm}$ \\
\hline Sampling interval & $20 \mathrm{~ns}$ & $3.3 \mathrm{~ns}$ & $15 \mu \mathrm{s}$ & $2.5 \mathrm{~ms}$ \\
\hline Digitizer depth & 12 bit & 8 bit & 12 bit & CCD readout \\
\hline Record duration/size & 0.41 or $0.82 \mathrm{~ms}$ & 4.37 or $8.74 \mathrm{~ms}$ & $1.9 \mathrm{~ms}$ & $128 \times 128$ macropixels \\
\hline Inter-record dead time & $\begin{array}{l}=\quad \text { record dura- } \\
\text { tion }+160 \mu \mathrm{s}\end{array}$ & $=$ record duration & $1.9 \mathrm{~ms}$ & $>2.5 \mathrm{~ms}$ \\
\hline $\begin{array}{l}\text { Trigger mode during } \\
\text { this study }\end{array}$ & $\begin{array}{l}\text { Autonomous, multi- } \\
\text { channel coincidence }\end{array}$ & Commanded by PDD & $\begin{array}{l}\text { Autonomous, level- } \\
\text { crossing }\end{array}$ & Autonomous \\
\hline Useful lifetime & Nov 1997-Dec 1999 & Nov 1997-Jun 2003 & Nov 1997-Dec 2008 & Nov 1997-Dec 2008 \\
\hline Reference & Jacobson et al. (1999) & Light et al. (2001a) & Kirkland et al. (2001) & $\begin{array}{l}\text { Suszcynsky et al. } \\
\text { (2001) }\end{array}$ \\
\hline
\end{tabular}

\subsection{Radio payloads}

One of the radio payloads was the "two-and-twentyreceiver", or TATR: a dual-channel 50-megasample s ${ }^{-1} 12$ bit digitized receiver, which had $22 \mathrm{MHz}$ analog bandwidth tuneable throughout the VHF (Jacobson et al., 1999). The TATR trigger was normally furnished by a sophisticated multichannel-coincidence system using eight $1 \mathrm{MHz}$-wide subbands, situated on $2.5 \mathrm{MHz}$ centers within the TATR passband. This multichannel trigger selected very effectively for broadband pulses, such as lightning. For data of the present study, the TATR was autonomously triggered by its own multichannel trigger system. The present study's passband was $26-48 \mathrm{MHz}$. In practice, however, the lower edge (26$29 \mathrm{MHz}$ ) of that passband was less sensitive to lightning radio signals, due to ionospheric refraction, even after a firstorder correction for dispersion. Thus the effective contributing passband within which we estimate the radio ERP was 29-48 MHz. Most of the TATR records for this study had $0.41 \mathrm{~ms}$ duration, though a few had $0.82 \mathrm{~ms}$. TATR functioned from 1997 through the end of 1999. More details of the TATR payload are available elsewhere (Jacobson et al., 1999).

The other radio payload was the "hundred-megahertz receiver", or HUMR: a single-channel 300-megasample s ${ }^{-1} 8$ bit digitized receiver (Light et al., 2001a). HUMR functioned from 1997 to mid-2003. The analog bandwidth was $85 \mathrm{MHz}$, selectable from three settings to cover three subregions of the VHF. HUMR lacked a multichannel trigger and, when autonomously triggered, used a single narrow subband within its subband for a simple rising-edge trigger. Compared to TATR, the HUMR autonomous trigger was quite susceptible to anthropogenic radio noise. However, for the present study we used HUMR records that were triggered by a signal deriving from the optical photometer's autonomous trigger, ensuring that all the HUMR recordings were of lightinggenerated radio signals, or at least coincident with optical signals from lightning. For this study, the HUMR passband was $0-85 \mathrm{MHz}$. The effective base frequency was imposed by the ionospheric cutoff and by the lower frequency of the LPA optimal response $(25 \mathrm{MHz})$. The lightning emitter's VHF ERP was estimated within a digital-filter passband of 29-48 MHz, to make the HUMR ERP directly comparable to TATR estimates of ERP. The HUMR records for this study had either 4.37 or $8.74 \mathrm{~ms}$ duration.

\subsection{Optical payloads}

The primary optical instrument for this study is the PDD (photodiode detector) wideband (0.4-1.1 micron) photometer (described in detail by Kirkland et al., 2001), whose field of view (FOV) was a nadir-centered circle of radius $\sim 600 \mathrm{~km}$ at lightning level. The PDD recorded the optical irradiance versus time, with $15 \mu$ s sampling steps. During all of the recordings used in this study, the PDD was autonomously triggered on its own background-compensated rising-edge trigger, and the duration was $1.9 \mathrm{~ms}$. Although shorter than the $6.85 \mathrm{~ms}$ in the earlier case study of 222 records (Light et al., 2001a), this short duration provided a greatly increased number of cases. All of this study's optical recordings were in nighttime darkness, assuring that the PDD trigger was almost always due to lightning (Kirkland et al., 2001).

The secondary optical instrument for this study is the LLS (lightning location system) imager (described in detail by Suszcynsky et al., 2001), which provided $128 \times 128$ macropixel maps of lightning with frame duration $\sim 2.5 \mathrm{~ms}$. The LLS front end was derived from, and used the same 
Table 2. HUMR-PDD waveform pairs with PDD control of HUMR trigger.

\begin{tabular}{ll}
\hline Number of pairs & 38212 \\
Number of pairs with LLS pixel event & 24517 \\
PDD waveform duration & $\sim 1.9 \mathrm{~ms}$ \\
HUMR duration & Either 4.37 or $8.74 \mathrm{~ms}$ \\
Subband for HUMR ERP time series & Matches TATR effec- \\
& tive bandpass \\
HUMR ERP time smoothing & $\sim 1.5 \mu \mathrm{s}$
\end{tabular}

technology as, the highly successful imager developed by Hugh Christian and colleagues at NASA Marshall Space Flight Center (Boccippio et al., 2000; Christian et al., 1989, 1999, 2003). The LLS macropixel dimension was $10 \mathrm{~km}$ on the ground at nadir. The LLS total FOV had an edge dimension matching the diameter of the PDD's FOV. For the data used in this study, the LLS was autonomously triggered.

All FORTE instrument characteristics for this study are summarized in Table 1.

\subsection{Los Alamos Sferic Array (LASA)}

LASA was a differential-time-of-arrival lightning-location and recording tool for lightning research (Shao et al., 2006; Smith et al., 2002, 2004). Starting in 1999, LASA provided excellent coverage of central Florida. This provided one season of joint observations with FORTE TATR satellite passes within view of the same Florida storms. While lacking a continental-scale operational capability such as that of the National Lightning Detection Network (Cummins et al., 1998; Cummins and Murphy, 2009), LASA provided close-in location of a lightning-prone area and, most importantly, recorded, stored and archived detailed lighting-stroke radiated waveforms in the frequency range $\sim 1-300 \mathrm{kHz}$. These waveforms, when compared with coincident FORTE TATR recordings of VHF emissions from the same event, allowed extensive study of the association of strong TIPPs with NBE strokes (Jacobson, 2003a, b; Jacobson and Light, 2003; Smith et al., 1999b). Later (2005 et seq) LASA also was deployed at several stations in the US Great Plains (Wiens et al., 2008). That latter deployment allowed a unique joint time-ofarrival/all-sky-optical observation of lightning.

\section{Data and results from the satellite data}

\subsection{Using HUMR as primary receiver: general}

During 2000-2003, much of the tasking of the HUMR instrument used an optically furnished trigger command. For the present study, we use HUMR radio recordings whose trigger was furnished by a rising optical transient from the PDD trigger. We include 38212 HUMR records, each with one accompanying PDD record. The PDD recording duration
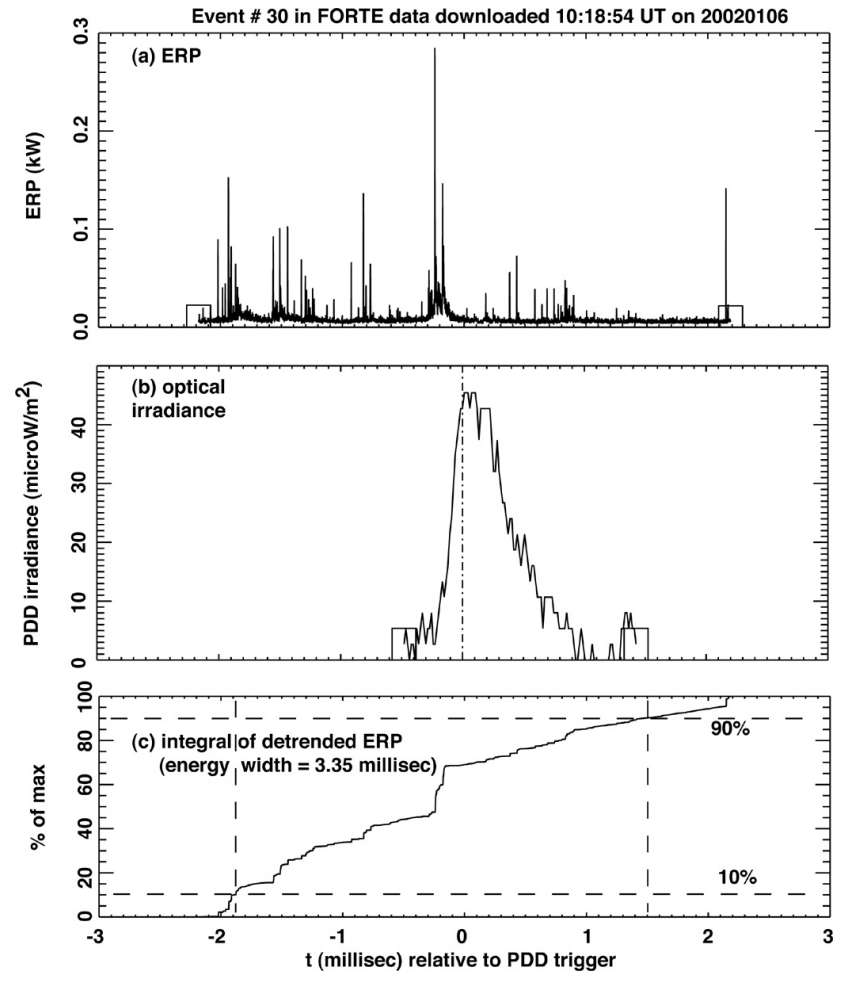

Fig. 1. Typical joint HUMR-PDD recordings, with HUMR triggered by PDD. (a) ERP versus time, with PDD trigger time defined as zero. (b) PDD optical irradiance versus time, with PDD trigger at zero (vertical dashed line). (c) Definite integral of ERP versus time, showing derivation of the "energy width" as the time between the definite integral's passages through $10 \%$ and $90 \%$ of its final peak value.

for this study was always $1.9 \mathrm{~ms}$, while the HUMR duration was variously 4.37 or $8.74 \mathrm{~ms}$. The HUMR could be "pretriggered" using a rotating buffer, so that the number of samples recorded before the trigger could be any programmed percentage of the total number of samples in the record.

Of the 38212 recording pairs, there were 24517 with LLS-furnished location within $\pm 0.1 \mathrm{~s}$ of the PDD trigger. For these events, we inferred the radio ERP directly from the slant distance from FORTE to the located lightning. For the other HUMR-PDD recording pairs, we approximated the source as lying at nadir, so that the distance to the source was approximated as the satellite altitude. This entails an overestimate of $r^{-2}$ by a factor of less than two (for the lightning at the extreme edge of the PDD's FOV), and less than that for lightning closer to nadir. Thus the ERP inferred for the events lacking LLS location may be biased low compared to the ERP for those cases with LLS support, though that difference will not be significant in the context of this study. Detailed information for these HUMR-PDD data is summarized in Table 2.

Figure 1 shows data from a typical HUMR-PDD recording pair. Like the majority of lightning detected optically 
from space (see, e.g., Boccippio et al., 2001), the causative lightning in Fig. 1 is an IC discharge. The ERP, shown versus time in Fig. 1a, is derived as follows: The radio electric-field recording is first compensated for ionospheric dispersion, or "dechirped" (Jacobson et al., 1999). The dechirped electric field is then digitally filtered to remove anthropogenic noise, including both quasi-steady carriers and repetitive-radar signals. Finally, this "cleaned" electric field is squared and smoothed over a $\sim 1.5 \mu$ s sliding window, and converted to an ERP using the satellite-to-lightning slant range. The PDDfurnished trigger to the HUMR recording arrived halfway through the $4.37 \mathrm{~ms}$ ERP record. The recording's endpoints are marked with square symbols. We note that the removal of radar pulses is new to this study and was not done for the earlier case study of 222 records (Light et al., 2001a). The removal of radar pulses is necessary so as to permit automated retrieval of the relative timing of VHF features with respect to the optical signal.

The ERP record in Fig. 1a contains many narrow impulses, some of which are arranged as pairs with an intra-pair separation of 50-70 $\mu$ s. In addition to the radio pulses, the ERP in Fig. 1a exhibits some more-slowly-varying features, such as the slow hump in the time range -0.5 to $0 \mathrm{~ms}$. These slower features underneath the narrow pulses have been noted before (Light et al., 2001a) and have been inferred to be possible manifestations of retrograde " $K$ "-type discharges (Shao and Krehbiel, 1996).

The accompanying PDD record of optical irradiance versus time is shown in Fig. 1b. Its record length is only $1.9 \mathrm{~ms}$, and the pretrigger samples are one-quarter of the record. The vertical dashed line marks the PDD trigger time, which we use as the zero-time reference, both for the PDD display and for the HUMR ERP display above it. The peak irradiance $\left(\sim 45 \mu \mathrm{W} \mathrm{m}^{-2}\right)$ is within the lower third of the PDD irradiance distribution documented elsewhere (Kirkland et al., 2001).

If a single TIPP dominates a radio recording, such as for the more familiar $0.41 \mathrm{~ms}$-long TATR recordings (Jacobson et al., 1999), the TIPP can be straightforwardly analyzed as follows: The electric field is dechirped and cleaned of noise, then squared, then smoothed with a sliding window of $\sim 1.5 \mu$ s duration. This smoothed $E^{2}$ series is then detrended so that the slowly varying background is removed, and we take the autocorrelation of the detrended series, out to a lag of $150 \mu \mathrm{s}$ (Jacobson et al., 1999). The autocorrelation gives three parameters. The first parameter is the halfwidth of the central peak. The second parameter is the delay of the TIPP echo (if there is an echo), while the third is the signal-to-noise ratio (SNR) of that echo feature relative to the rms statistical noise of the autocorrelation (Jacobson et al., 1999, 2011). In cases where the lightning has been geolocated either by the LLS or by coincidence with groundbased lightning-detection networks (see, e.g., Jacobson et al., 2000), the TIPP echo delay can be used to infer the discharge height above the reflective ground.
However, the complexity of the ERP time series in Fig. 1a prevents the autocorrelation-based TIPP analysis from being as useful in the present case. The autocorrelation signature is useful only in those cases where there is a single TIPP dominating the record, and that is not the case in Fig. 1a. The temporal overlap of many TIPPs confuses their identification as paired pulses.

We define an "energy width" as the single portion of the record within which is contained $80 \%$ of the total energy within the record. This is done by computing the definite integral of the background-suppressed ERP versus time. This definite integral increases monotonically versus time. We identify the energy width as the difference between the time when the definite integral passes through $90 \%$ of its maximum value and the time when it passes through $10 \%$. Figure $1 \mathrm{c}$ shows the definite integral, with vertical dashed lines indicating the times at which the integral passes through $10 \%$ and $90 \%$ of its final maximum value. The derived energy width in this example event is $3.35 \mathrm{~ms}$.

\subsection{Using HUMR as primary receiver: effect of trigger bias}

By requiring the HUMR to be externally triggered by the PDD trigger, we ensure that the HUMR radio recording is not biased by its own need to furnish an autonomous trigger. Thus, very weak radio signals might be expected to occur within the HUMR data triggered in this way, weaker than the autonomous-trigger threshold. We test this now for the 15257 recorded waveforms for which the TIPP echo SNR is $>3$. Although we cannot retrieve TIPP parameters adequately with such a low threshold of SNR, we can at least infer that the events are IC. Figure $2 \mathrm{a}$ shows the distribution of $\log _{10}$ (peak ERP) in these candidate IC HUMR records. The "peak" ERP is the peak within a given record, so that, for example, the peak ERP in Fig. 1a is $\sim 0.28 \mathrm{~kW}$, which is near the most-likely ERP in the distribution of Fig. 2a. We compare in Fig. $2 b$ the distribution of peak ERP for TATR events that are triggered autonomously but which occur in coincidence with joint PDD-LLS detections, reported in an earlier publication (see Fig. 7 in Jacobson, 2003a). This distribution in Fig. 2b is shifted toward higher ERP by about an order of magnitude, relative to the PDD-triggered HUMR cases of Fig. 2a. This difference of an order of magnitude is directly due to the fact that autonomously triggered radio data is systematically biased toward stronger radio signals, relative to when the trigger is externally furnished by $P D D$.

Figure $2 \mathrm{~b}$ requires some further background information. During the two years (1998 and 1999) of simultaneous autonomously triggered LLS and autonomously triggered TATR recordings, we have tabulated all LLS lightning events to see what portion are accompanied by simultaneous VHF signals that trigger the TATR and are recorded. The percentage of LLS events with VHF coincidence is only $\sim 15 \%$. Put another way, $\sim 85 \%$ of LLS events within 


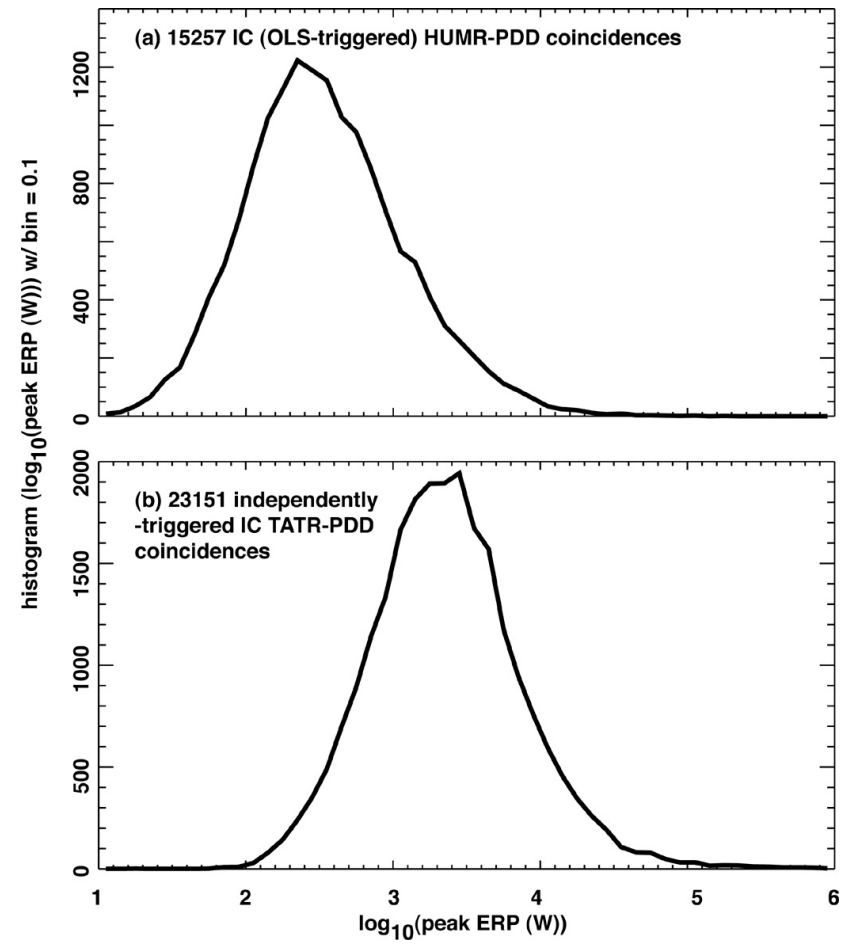

Fig. 2. Histogram of $\log _{10}$ (peak $\left.\operatorname{ERP}(\mathrm{W})\right)$, with bin size $=0.1$. (a) 15257 TIPPs from HUMR records triggered by PDD. (b) 23151 autonomously triggered TIPPs from TATR records coincident with autonomously triggered PDD. Note that, because only TIPPs are included, the data in this figure are exclusively from intracloud lightning.

$\pm 200 \mathrm{~ms}$ of a TATR event probably lack a physically coincident TATR event. Thus the majority of optical signals recorded by FORTE are not accompanied by VHF capable of triggering the extremely sensitive TATR trigger system (Jacobson et al., 1999). It should not be surprising, therefore, that the optically triggered VHF (Fig. 2a) is significantly less intense than the autonomously triggered VHF that is also optically coincident (Fig. 2b). The autonomously triggered VHF records contain mainly the high-power tail (top $\sim 15 \%$ ) of the underlying VHF intensity distribution.

\subsection{Using HUMR as primary receiver: radio-optical temporal relationship}

We now select within the HUMR IC data those records in which the radio energy distribution is narrow compared to the record duration, that is, any record in which a single TIPP dominates the record. We described the definition of "energy width" in Fig. 1c. Two more parameters are used to select records: ERP, and TIPP echo SNR. We expect that, jointly, the three parameters (energy width, ERP and SNR) can be thresholded to select for records with a dominant single TIPP, because of the following three trends. First trend: the energy width of a single TIPP ( $<0.15 \mathrm{~ms}$ ) (Jacobson et al., 1999) is much smaller than for a complex multifeature record such as, e.g., in Fig. 1, where the width is $3.35 \mathrm{~ms}$. Second trend: a dominant single TIPP gives a sharper echo signature in the autocorrelation of $E^{2}$ (see Fig. 1 in Jacobson et al., 2011). Third trend: a stronger TIPP results in a greater ERP.

Thus we use a selector based on imposing simultaneously a minimum ERP, a minimum echo (see Fig. 1c) SNR, and a maximum energy width within each of six levels of restriction. The least restrictive selection has $\mathrm{ERP}>0.1 \mathrm{~kW}$, $\mathrm{SNR}>3$, and energy width $<0.5 \mathrm{~ms}$. The most restrictive selection has ERP $>50 \mathrm{~kW}, \mathrm{SNR}>100$, and energy width $<0.15 \mathrm{~ms}$. Table 3 summarizes (in bold type) the six successive levels of restriction in the selection for records dominated by a single TIPP event. In addition to the six selectors, the effect of a step in each individual parameter separately is shown (in plain type), for the cases in which more than one parameter is stepped in going from one of the six selectors to the next of the six selectors. These six selectors very effectively find the minority of records in which a single TIPP tends to dominate the record. Even for the least restrictive selector, the number of qualifying events (1010) is small compared to the candidate pool of nominal TIPPs (15 257). The number of qualifying events then further declines monotonically as the criteria become more restrictive (see Table 3). In the most restrictive case (ERP $>50 \mathrm{~kW}$, SNR $>100$, and energy width $<0.15 \mathrm{~ms}$ ), there are only six events. This scarcity of strong TIPPs in the data set used here is due to the lack of a VHF trigger-threshold bias. We are simply recording $\mathrm{VHF}$ in this data set whenever there is an optical trigger; no VHF-derived trigger is needed. In 15257 recorded waveforms for which the TIPP echo SNR is $>3$, and in which therefore we may reasonably assume that the discharge is $\mathrm{IC}$, only six records $(0.04 \%)$ contain a dominant "strong TIPP" that is relatively common in autonomously triggered FORTE VHF records, whether TATR or HUMR. For autonomously triggered TATR VHF records from FORTE, it has been shown that of $\sim 1$.5-million IC records with autonomous triggering, there were $\sim 17$ thousand records with a single dominant strong TIPP (similar to the six found here), or $\sim 1 \%$ of the total IC candidate pool (Jacobson and Light, 2003). Therefore the $0.04 \%$ rate of dominant strong TIPPs found here with the optically commanded HUMR trigger represents a reduction by a factor of $1 / 25$ due to the difference between optically controlled and autonomous triggering.

For each of these six classes of TIPP selection, we calculate the internal median (in that class) of the ERP and the internal median of the energy-weighted VHF center time, relative to the PDD trigger time. Figure 3 shows the classmedian time difference (vertical) versus class-median ERP. Points that are lower on the vertical axis occur earlier before the PDD trigger. Points that are higher on the vertical axis occur closer (though still before) the PDD trigger. For the four least restrictive classes, the class-median VHF time is earlier than the PDD trigger by not more than $0.2 \mathrm{~ms}$. However, for 
Table 3. HUMR TIPP filters shown in bold type. When more than one parameter is varied between adjacent TIPP filters, the contributions of varying each parameter individually are shown in the remaining rows (non-bold type).

\begin{tabular}{|c|c|c|c|c|c|c|}
\hline Filter\# & $\mathrm{ERP}>$ & Echo SNR > & Energy width $<$ & Number of TIPPs & VHF before optical & VHF after optical \\
\hline 1 & $0.1 \mathrm{~kW}$ & 3 & $0.5 \mathrm{~ms}$ & 1010 & 891 & $119(12 \%)$ \\
\hline \multirow[t]{3}{*}{2} & $1 \mathbf{k W}$ & 3 & $0.5 \mathrm{~ms}$ & 784 & 686 & $98(13 \%)$ \\
\hline & $5 \mathrm{~kW}$ & 3 & $0.5 \mathrm{~ms}$ & 226 & 93 & $33(15 \%)$ \\
\hline & $5 \mathrm{~kW}$ & 10 & $0.5 \mathrm{~ms}$ & 181 & 152 & $29(16 \%)$ \\
\hline 3 & $5 \mathrm{~kW}$ & 10 & $0.15 \mathrm{~ms}$ & 133 & 116 & $17(13 \%)$ \\
\hline \multirow[t]{2}{*}{4} & $10 \mathrm{~kW}$ & 10 & $0.15 \mathrm{~ms}$ & 66 & 58 & $8(12 \%)$ \\
\hline & $30 \mathrm{~kW}$ & 10 & $0.15 \mathrm{~ms}$ & 19 & 18 & $1(5 \%)$ \\
\hline \multirow[t]{2}{*}{5} & $30 \mathrm{~kW}$ & 50 & $0.15 \mathrm{~ms}$ & 17 & 17 & $0(0 \%)$ \\
\hline & $50 \mathrm{~kW}$ & 50 & $0.15 \mathrm{~ms}$ & 7 & 7 & $0(0 \%)$ \\
\hline 6 & $50 \mathrm{~kW}$ & 100 & $0.15 \mathrm{~ms}$ & 6 & 6 & $0(0 \%)$ \\
\hline
\end{tabular}

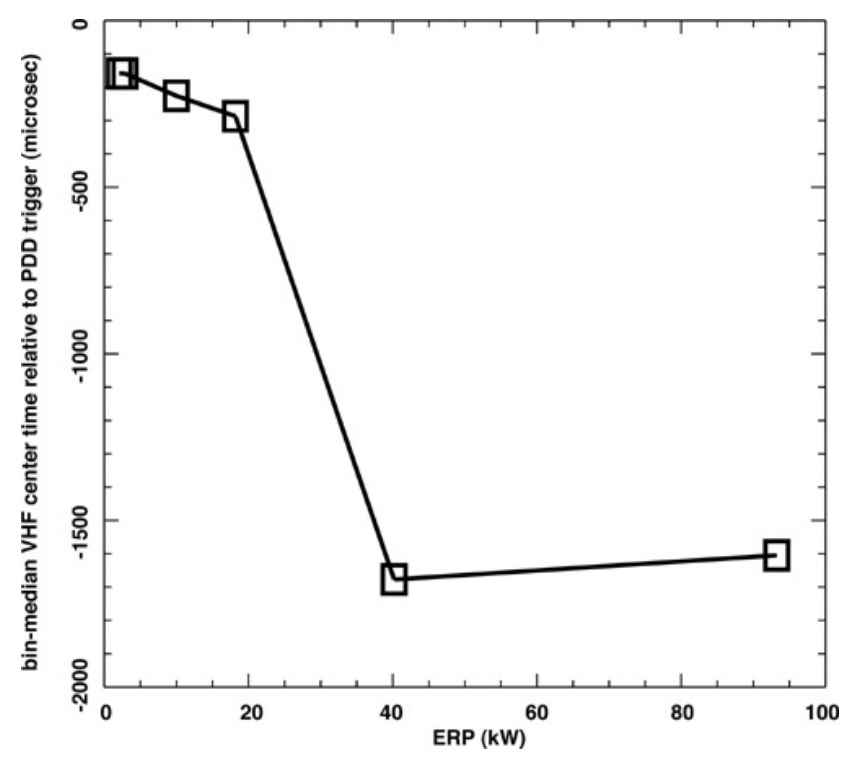

Fig. 3. Within-class median time difference, versus within-class median ERP, for HUMR TIPPs. Classes defined in Table 3.

the most restrictive classes, the VHF time jumps earlier, to $>1.5 \mathrm{~ms}$ earlier than the PDD trigger.

Notice that the median time difference (HUMR minus PDD) is negative for all levels of TIPP selection. Table 3's last three columns show that not only is the median time difference negative but also that the individual cases with negative time difference greatly outnumber the cases with positive time difference. For the less restrictive four classes, the percentage of individual cases where the VHF lags the optical trigger is $12 \%$ to $13 \%$. For the more restrictive two classes, there are zero (0) cases where the VHF lags the optical, of the total number of events (23) in those classes.

The measured optical signal's delay (relative to the VHF signal) has previously been shown to consist of two additive contributions (Light and Hamlin, 2008; Suszcynsky et al., 2000): First, there is a "scattering" delay (of the light relative to the VHF) due to the multiple Mie scatterings during trans- port through the cloud to the cloud's top, where the light can be seen from orbit (Koshak et al., 1994; Light et al., 2001b). For an ensemble containing hundreds of examples of joint radio and optical recordings, the temporal broadening due to scattering was estimated as $138 \mu$ s (see Fig. 3 in Suszcynsky et al., 2000). This broadening slows down both the rise and fall phases of the optical pulse seen at cloud-top, relative to the pulse at the actual source. For a rising-edge optical trigger, the broadening due to scattering causes a delay in the occurrence of the trigger. We stress that the $138 \mu$ s broadening was determined solely for the limited data set used in the study (Suszcynsky et al., 2000), that it was not tested with widely differing datasets, and that the broadening may be far less stable a parameter than implied by 3 significant figures cited. The second additive contribution is the "physical delay", which depends on discharge type. The physical delay is the delay of the optical source relative to the VHF source, independent of scatter. It has been estimated to be on the order of $60 \mu \mathrm{s}$ for cloud-to-ground return strokes and on the order of $-30 \mu$ s for intracloud discharges (Light and Hamlin, 2008; Suszcynsky et al., 2000). The scattering delay may affect the top-left end of the curve in our Fig. 3, corresponding to the least restrictive filters from Table 3 . That is, much of the apparent delay at the left intercept (optical lagging VHF by $\sim 150 \mu \mathrm{s}$ ) may be due to scattering. Likewise, an optical signal lagging a VHF signal by as little as a few tens of microsec could be simultaneous with the VHF at the source discharge within the cloud.

The transition in Fig. 3, from small time difference for weak TIPPs to large time difference for strong TIPPs, depends on small numbers of rare events. Thus it is advisable to examine each of the six events in the most restrictive class (strongest TIPPs), in order to gain some insight into the jump in time difference. Table 4 identifies the six events and gives the time difference (median HUMR minus PDD), which is negative because the HUMR energy-weighted center time is earlier than the PDD trigger time. It has been observed in the past that dominant strong TIPPs, corresponding to the most restrictive category in Table 3, are highly unlikely to 
Table 4. Filter \# 6 HUMR events.

\begin{tabular}{clcc}
\hline Index & Original DAS file & Event $n$-th in DAS file & TIPP - PDD median time difference \\
\hline 0 & f20001205_164334.das & 43 & $-5.20 \mathrm{~ms}$ \\
1 & f20001207_192435.das & 16 & $-2.25 \mathrm{~ms}$ \\
2 & f20010730_125824.das & 80 & $-1.60 \mathrm{~ms}$ \\
3 & f20020227_161225.das & 286 & $-0.89 \mathrm{~ms}$ \\
4 & f20020422_225121.das & 109 & $-0.30 \mathrm{~ms}$ \\
5 & f20020814_220349.das & 134 & $-1.75 \mathrm{~ms}$ \\
\hline
\end{tabular}
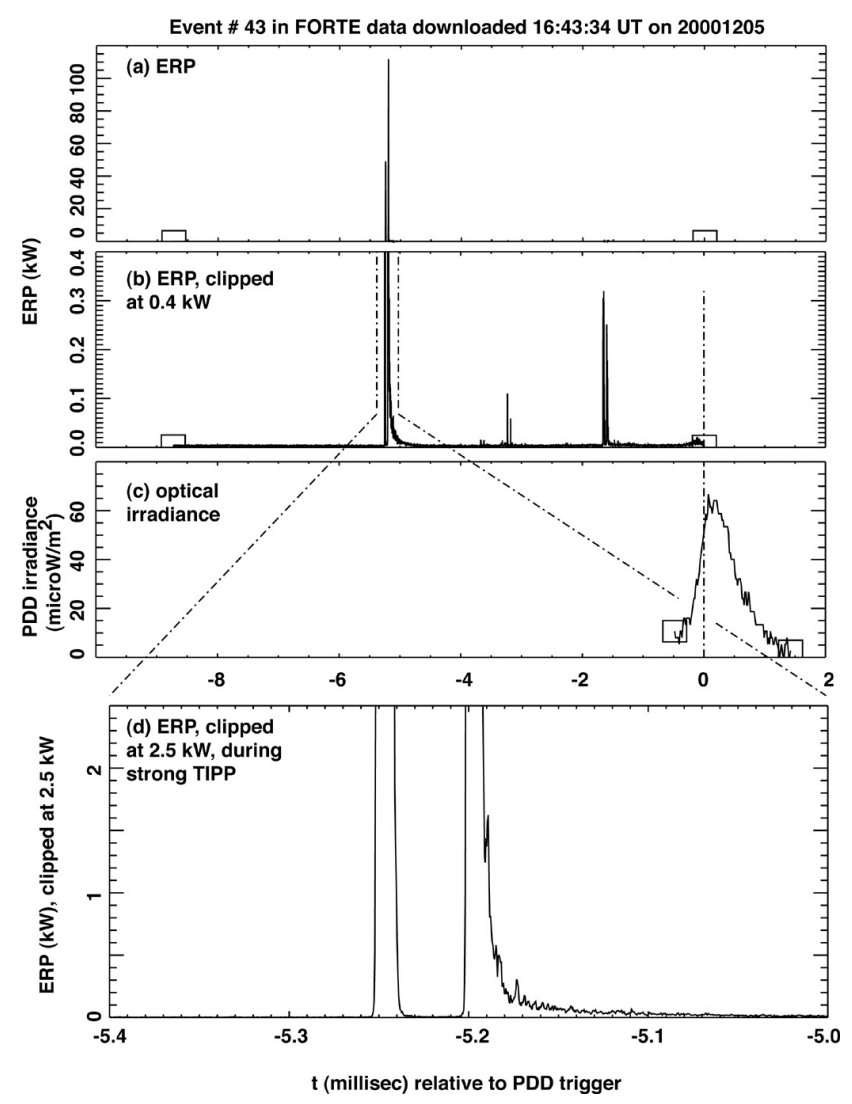

Fig. 4. First of the six HUMR-PDD events of Table 4. (a) ERP vs. time. Square symbols mark the start and stop of the record. Time is referenced to 0 at the PDD trigger time. (b) ERP vs. time, clipped at $0.4 \mathrm{~kW}$ on the ordinate. (c) Optical irradiance vs. time, with the trigger time marked by a vertical dashed line. (d) ERP vs. time, clipped at $2.5 \mathrm{~kW}$ on the ordinate, and restricted to the zoom limits marked in panel (b).

produce enough light to trigger PDD (Jacobson and Light, 2012; Light and Jacobson, 2002). Thus, the finding that six strong TIPPs are associated with measurable optical emission may not be consistent with previous findings, and thus requires examining these six events in detail.

Figure 4 examines the first of the six strongest-TIPP cases, for which case the VHF energy center occurs at time $-5.2 \mathrm{~ms}$ relative to the PDD trigger. Figure 4a shows ERP versus time,

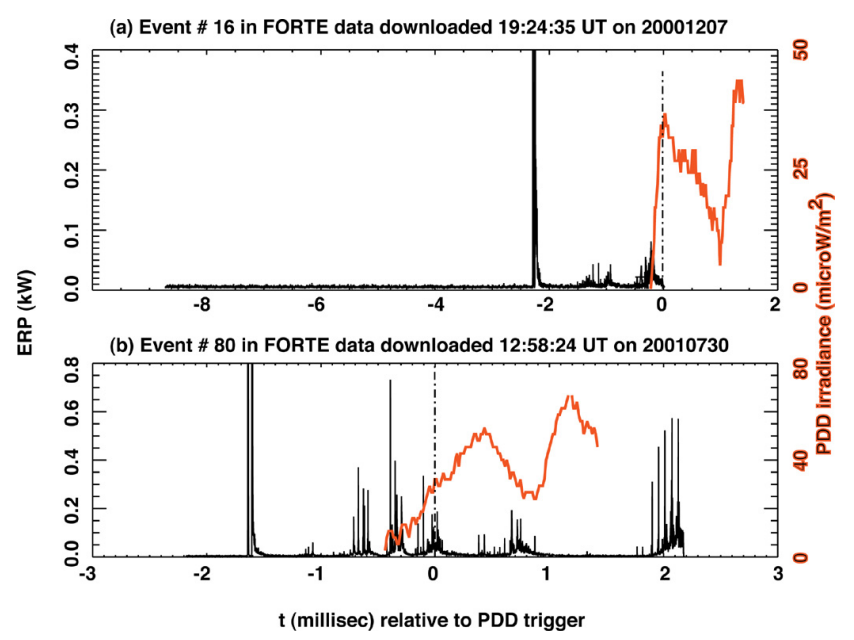

Fig. 5. ERP versus time (black) and optical irradiance versus time (orange) for (a) the second and (b) the third of the six HUMR-PDD events of Table 4 . The dashed vertical lines mark the PDD trigger time, defined as zero.

and indicates that the VHF record is dominated by a single pulse pair of very high peak ERP $(>100 \mathrm{~kW})$. That the second peak can be higher than the initial peak is understood. The directly progagating signal (the first peak) is on average stronger than the reflected component, but the polarizationsensitive ground reflection, as well as the transmission lobe of a dipole emitter, can cause the reflection sometimes to exceed the direct signal (see explanations in Jacobson et al., 2011; Tierney et al., 2002).

Figure $4 \mathrm{~b}$ again shows ERP versus time, but with ordinate clipped at $\mathrm{ERP}=0.4 \mathrm{~kW}$. This increase in ordinate gain reveals a series of very weak secondary TIPP events following the strong TIPP. The first visible weak TIPP begins about $1 \mathrm{~ms}$ after the strong TIPP. The Lightning Mapping Array (LMA) at New Mexico Tech first observed that a small minority of strong VHF IC pulses (TIPPs when seen from space) can initiate an intracloud flash, in which the intial strong pulse (TIPP if seen from space) is followed by a series of irregularly spaced leader steps (see Fig. 2 in Thomas et al., 2001). This was confirmed by an analysis of autonomously triggered TATR and PDD data from FORTE (Jacobson, 2003a), in which the flash-initiating strong TIPPs 
produced no light capable of triggering PDD, while the ensuing weak TIPPs from leader steps were often luminous enough to trigger the PDD (see Fig. 15 in Jacobson, 2003a). Thus it appears that the weak TIPPs following the strong TIPP in Fig. 4b are consistent with what was seen earlier with both LMA and autonomously triggered TATR. Indeed, Fig. 4c, showing the PDD irradiance versus time, indicates that the pulse train of weak TIPPs are temporally associated with the light emission, which rises out of the noise at the start of the PDD record.

The time interval following the main pulse of the strong TIPP, but prior to the arrival of the ground-reflection echo, is the earliest chance to examine the record for weak secondary discharges initiated by the main pulse. Figure $4 d$ shows an expanded view of the strong TIPP, for a $0.4 \mathrm{~ms}$ duration on the abscissa and clipped at $2.5 \mathrm{~kW}$ on the ordinate $(\sim 2 \%$ of the peak ERP). The intra-TIPP period shows no observable secondary radio emissions. The reflection echo shows an extended coda, due to rough-surface scattering that involves longer total pathlengths than the main specular reflection. This strong TIPP is typical of the majority of TATRobserved strong TIPPs, with ERP $>40 \mathrm{~kW}$ in the reference passband (29-48 MHz), with a simple structure lacking any observable secondary breakdown or optical emission within the tens of microsec of the primary pulse (Jacobson, 2003b; Jacobson and Light, 2003).

Figure 5 examines (a) the second and (b) the third of the cases of a strong TIPP (the most restricted category in Table 3). Shown in black is the ERP versus time, clipped in the vertical axis to reveal trains of secondary-breakdown pulses following the main TIPP, whose unclipped peak ERP is on the order of $100 \mathrm{~kW}$. Shown in orange is the optical irradiance versus time. In each panel in Fig. $5, t=0$ occurs at the PDD trigger, marked by a vertical dashed line. In each case, the optical is seen to be associated with the secondarybreakdown pulse trains, rather than with the initial, dominant TIPP.

The first three strong-TIPP cases (Figs. 4 and 5) from Table 4 all exhibited a strong "clean" TIPP that was followed, with a delay of half a millisec or more, by a sequence of weaker IC emissions, temporally associated with the optical irradiance. The last three strong-TIPP cases, however, depart from this pattern. Each of the last three cases exhibits prompt (within tens of microsec) secondary breakdown following the dominant IC pulse. Two of these three show prompt optical irradiance as well.

Figure 6 presents (a) ERP, (b) optical irradiance, and (c) close-in ERP for the fourth strong-TIPP case in Table 4. The irradiance is already at half its maximum value at the start of the record, so it cannot be excluded that optical emission had started during the TIPP itself. Figure $6 \mathrm{c}$ shows a new feature, not seen in the first three cases: Within $\sim 20 \mu$ s of the fall of the primary pulse, there is a prominent secondarybreakdown pulse (marked with an arrow). Indeed, there are two even weaker secondary-breakdown pulses, one on ei-
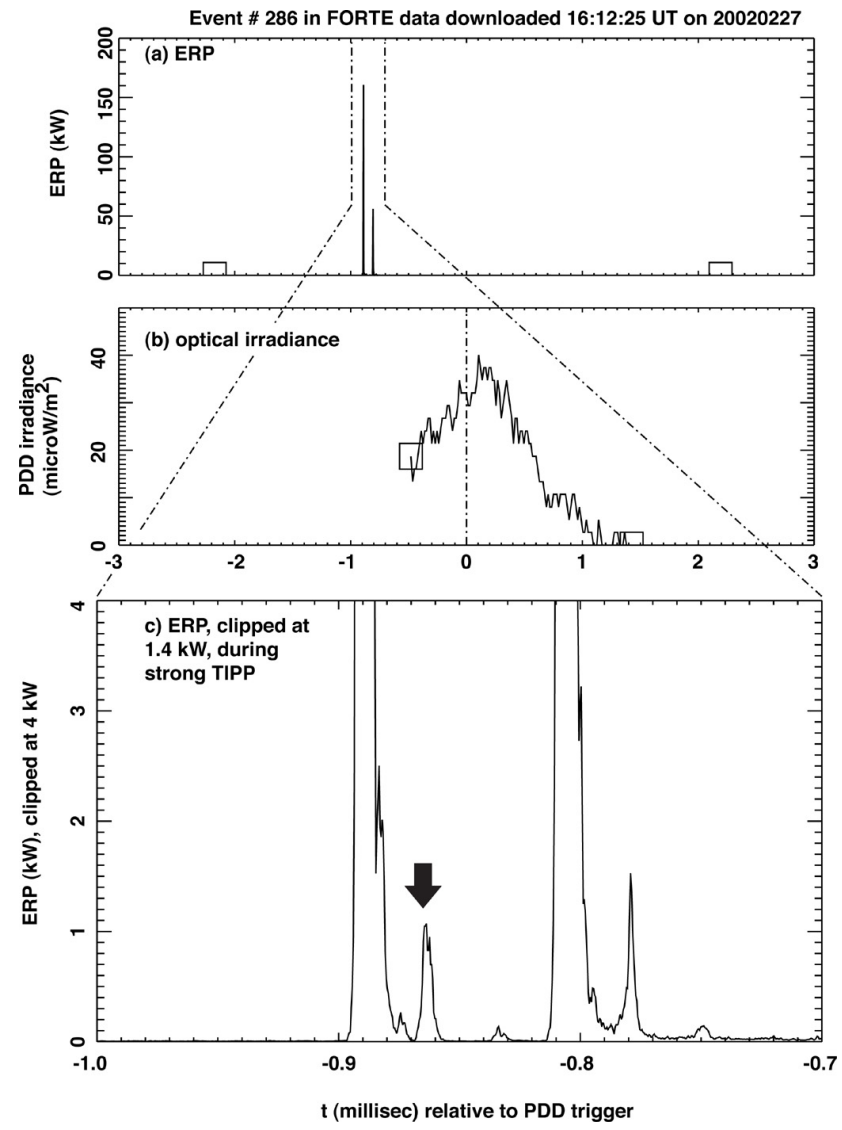

Fig. 6. Similar to Fig. 4, but for the fourth of the six HUMR-PDD events of Table 4. Arrow marks a "secondary-breakdown pulse".

ther side of the marked pulse. All three of the secondarybreakdown pulses are visible also in the echo, as would be expected.

Figure 7 presents (a) ERP, (b) optical irradiance, (c) closein ERP, and (d) close-in optical irradiance for the fifth strongTIPP case in Table 4. Unlike Fig. 6 above, here the optical record begins at the base of the optical rising edge, so that we can see clearly when the observable irradiance exceeded the noise. Comparison of Fig. 7c, d shows clearly that the secondary-breakdown pulse (marked with an arrow) precedes the rise of irradiance.

Figure 8 presents (a) ERP, (b) clipped ERP, (c) optical irradiance, and (d) close-in ERP for the final strong-TIPP case in Table 4. The optical record begins near the peak of rising edge, so there is no way of telling when the optical irradiance had begun to rise. However, there is a clear secondarybreakdown sequence (see arrow in Fig. 8d) starting within $20 \mu$ s after the primary pulse.

We summarize these findings:

1. As the ERP increases through the six classes, the HUMR-PDD median time difference transitions to more deeply negative. 


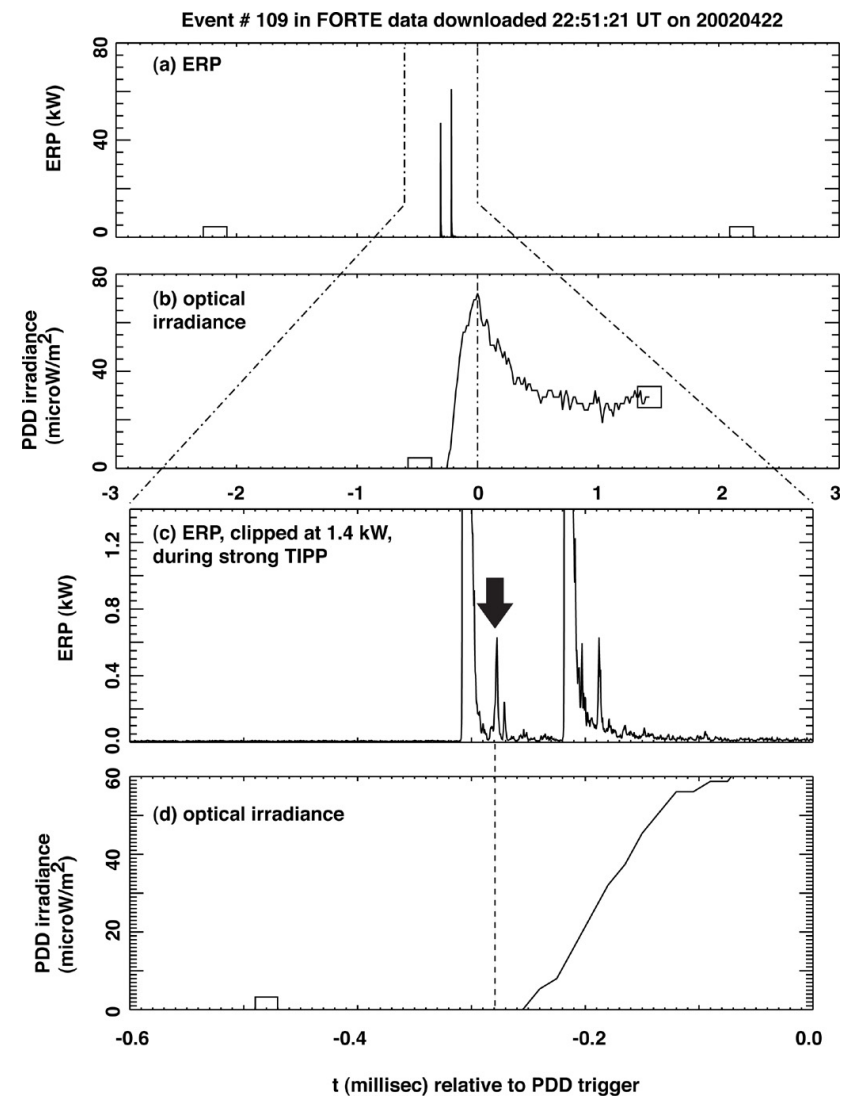

Fig. 7. Fifth of the six HUMR-PDD events of Table 4. (a) ERP vs. time. (b) Optical irradiance vs. time. (c) ERP vs. time, clipped at $1.4 \mathrm{~kW}$ on the ordinate and restricted to the zoom limits shown in panel (a). (d) Optical irradiance, restricted to the same time limits as panel (c). Arrow marks a "secondary-breakdown pulse" in panel (c), which is continued as a dashed line in panel (d).

2. There are only six events in the strongest-TIPP category, representing $\sim 0.04 \%$ of the candidate IC cases in the optically triggered HUMR archive. This is to be compared with $1 \%$ of the candidate IC cases in earlier studies of TATR records triggered autonomously.

3. Of the six events in the strongest-TIPP category, three (Figs. 4 and 5) have a clear separation between the rise of the irradiance and the main TIPP itself. These three cases have extended trains of secondary-breakdown pulses and slower features that are temporally close to the light emission. These three TIPPs have no sign of prompt secondary breakdown between the primary peak and its echo.

4. The other three events (Figs. 6-8) in the strongest-TIPP category have irradiance that apparently begins close in time to the main TIPP. However, all of these three cases also have a novel radio feature - the prompt onset of secondary breakdown pulse(s) within tens of microsec of the main pulse.

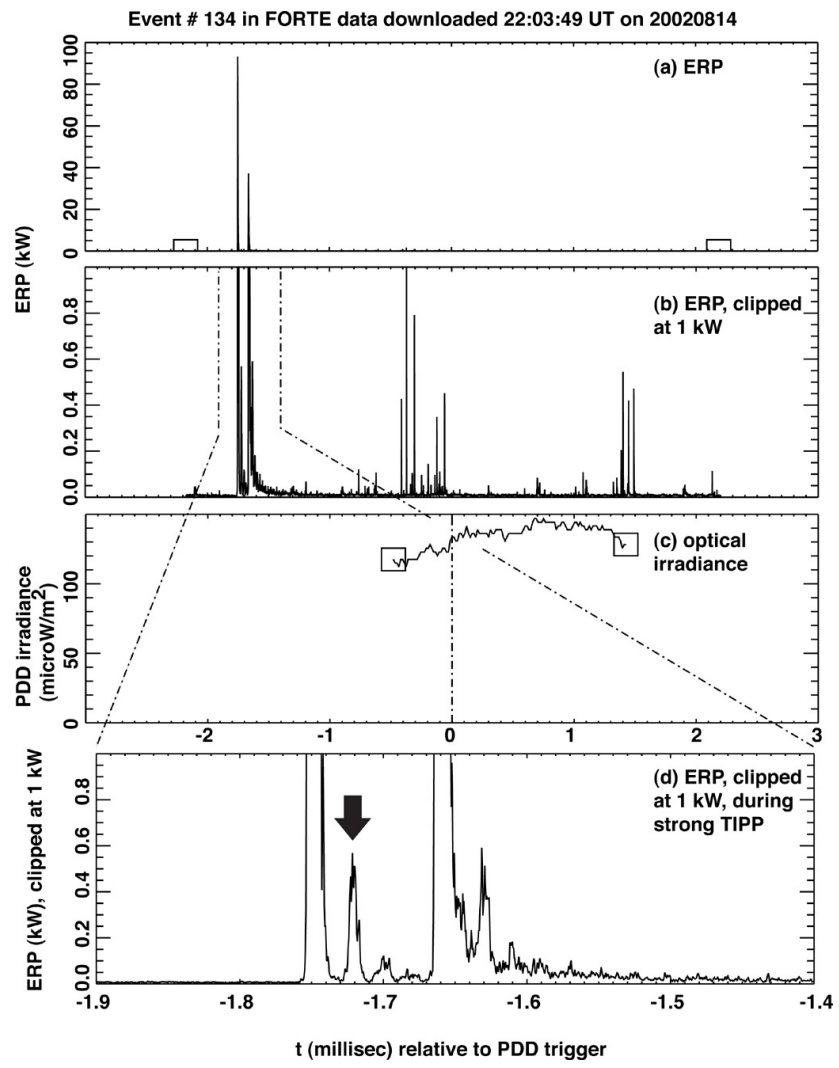

Fig. 8. Last of the six HUMR-PDD events of Table 4. (a) ERP vs. time. (b) ERP vs. time, clipped at $1 \mathrm{~kW}$ on the ordinate. (c) Optical irradiance vs. time. (d) ERP vs. time, clipped at $1 \mathrm{~kW}$ on the ordinate and restricted to the zoom limits shown in panel (b).

\subsection{Comparison with TIPPs recorded by autonomously triggered TATR}

The findings with the optically triggered HUMR records of TIPPs, summarized above, are now compared to autonomously triggered TATR records of TIPPs. We consider all autonomously triggered TATR records with loosely coincident PDD triggers (within $\pm 200 \mathrm{~ms}$ of the TATR trigger). There are 124786 such TATR records, of which 41720 are TIPPs with SNR $>10$.

Of these 41720 TIPPs, let us define two separate and disjunct classes: (a) strong TIPPs, with $\mathrm{SNR}>50$ and ERP $>40 \mathrm{~kW}$, and (b) weak TIPPs, with SNR $>10$ and ERP $>4 \mathrm{~kW}$. The strong TIPPs number 798 records $(\sim 2 \%$ of 41720 TIPP records), while the weak TIPPs number 31557 records. Figure 9 shows the distribution of PDDTATR trigger times for (a) the 31557 weak TIPPs and (b) the 798 strong TIPPs. It is clear that PDD triggers near strong TIPPs (see Fig. 9b) predominantly occur after the TIPP, and that the level of occurrence prior to the TIPP is indistinguishable from the accidental-correlation (statistical-noise) level. This cannot be said for the weak TIPPs (see Fig. 9a), for which the distribution, while not symmetric, still has 


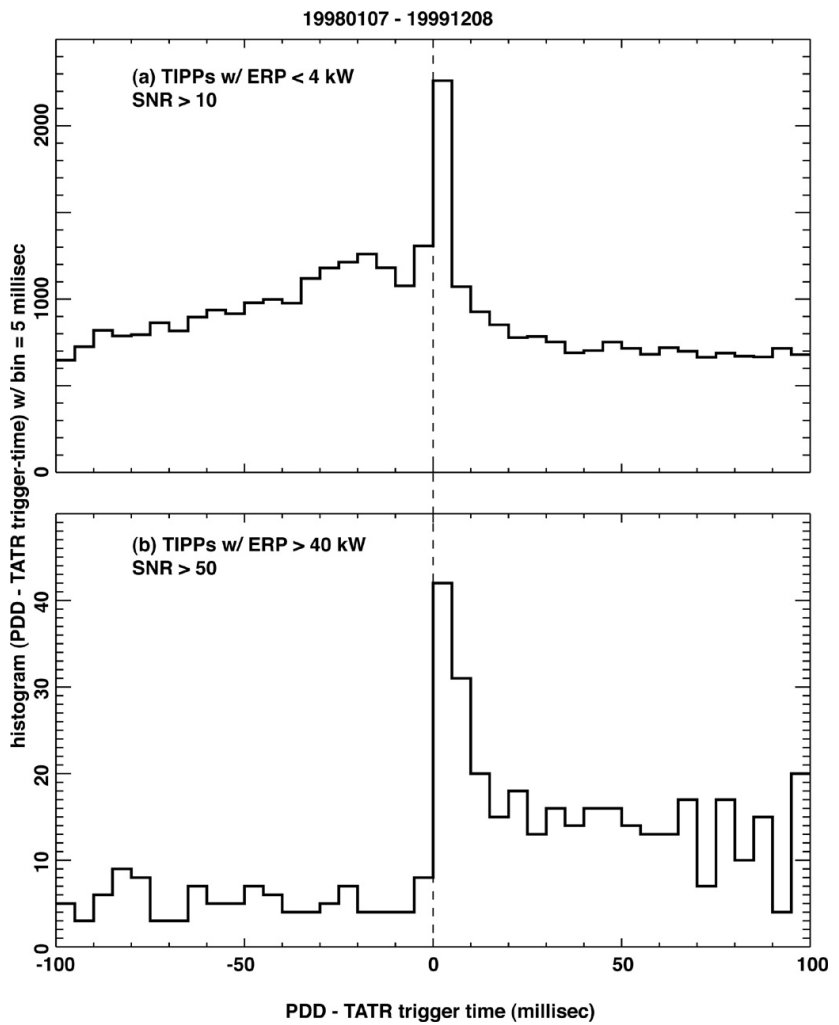

Fig. 9. Histograms of PDD-TATR trigger-time differences, for autonomously triggered TATR and autonomously triggered PDD. (a) Weak TIPPs. (b) Strong TIPPs.

significant numbers of PDD triggers on either side of the TIPP trigger. This timing relationship between PDD and very strong TIPPs is thus similar for both TATR records triggered autonomously (this section) and long HUMR records controlled by PDD (previous section).

We now study in more detail the circumstances under which the strong TATR TIPPs have temporally close PDD triggers. Of the total 798 TATR strong TIPPs, there are eight with accompanying PDD triggers occurring in the range 0.0 to $0.3 \mathrm{~ms}$ after the TIPP trigger (which is generally the first pulse of the pulse pair). Figure 10 shows the mean square electric field (where the mean is over a sliding $1.5 \mu$ s window) versus time for event index 2, first (a) full range on the ordinate, then (b) clipped at $2 \%$ of full range. The arrow shows a prominent secondary-breakdown pulse occurring promptly, $\sim 20-30 \mu$ s after the first pulse. This secondarybreakdown pulse on the TATR TIPP is similar to the prompt secondary-breakdown pulse seen with HUMR in Figs. 68 above. In order to display all eight strong TIPPs in one figure, we graph in Fig. 11 the root mean square electric field versus time. The square root provides enough compression to indicate the presence of secondary-breakdown pulses, though it is not as sensitive as a clipped $E^{2}$ display (such as in Fig. 10b) to see the detailed shape of the secondary pulse. The TIPP shown in Fig. 10 appears in Fig. 11c. All of

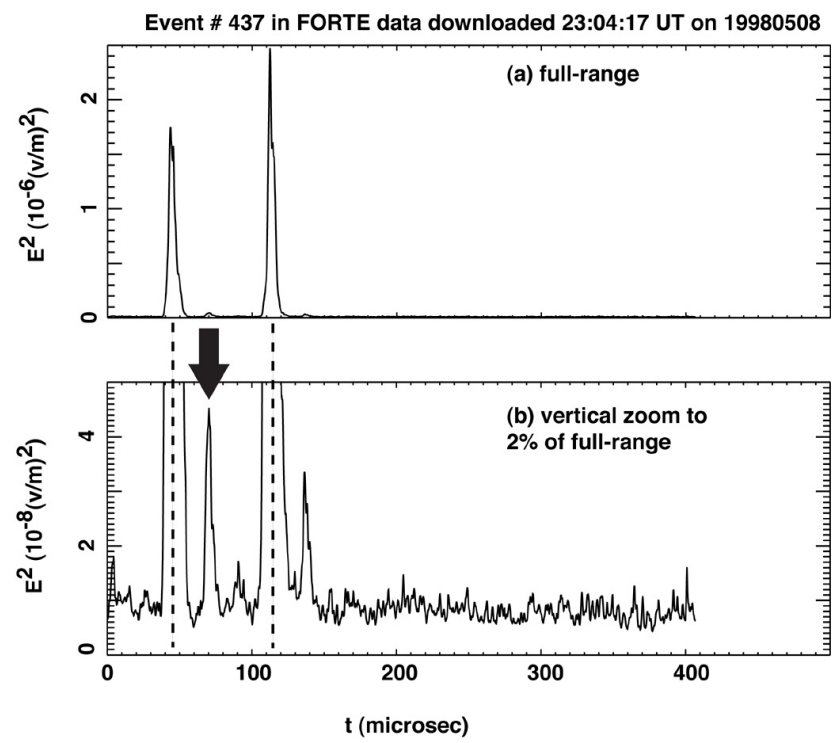

Fig. 10. An autonomously triggered TATR record that is coincident with autonomously triggered PDD. (a) Squared electric field vs. time, averaged over a $1.5 \mu$ s sliding window. (b) Squared electric field vs. time, clipped to $2 \%$ of full range. Vertical dashed lines mark the TIPP main pulse and echo. Arrow marks a "secondarybreakdown pulse". Same TATR record as shown below in Fig. 11c.

the eight strong TIPPs in Fig. 11 have secondary-breakdown pulses promptly (delay $\sim$ tens of microsec) following the primary peak. Two of these TIPP records $(d, e)$ also have prebreakdown pulses, something we have never seen before in the context of strong TIPPs.

Finally, we perform a control test, examining TATR strong TIPPs that are coincident not with optical irradiance but with NBEs recorded by LASA in Florida during 1999 (Smith et al., 2002, 2004). To allow easier examination of the time window between the primary pulse and the ground-reflection echo, we require that the TIPP echo delay exceed $70 \mu$ s. This permits us to search for prompt secondary-breakdown pulses during at least $70 \mu$ s before they would be masked by the echo signal. We thus impose the following extremely stringent requirements: tight coincidence with LASA-recorded NBE discharges, ERP $>70 \mathrm{~kW}$, echo SNR $>50$, and TIPP separation $>70 \mu$ s. These requirements are met by 26 TATR recordings during 1999. Taken as a whole, they are mostly but not entirely - free of secondary-breakdown pulses. Figure 12 shows the root mean square electric field versus time, for the first four of these 26 recordings. None of these first four recordings shows a prompt secondary-breakdown pulse visible above the noise. Of the remaining 22 recordings, only four (4) show prompt secondary-breakdown pulses which rise above the noise, similar to those seen in Fig. 11.

Other authors (Rison et al., 1999; Wu et al., 2011) have shown that occasionally NBEs can initiate otherwise "ordinary" flashes. All of the cases in Fig. 11 above may be such flash initiators as they observed. 

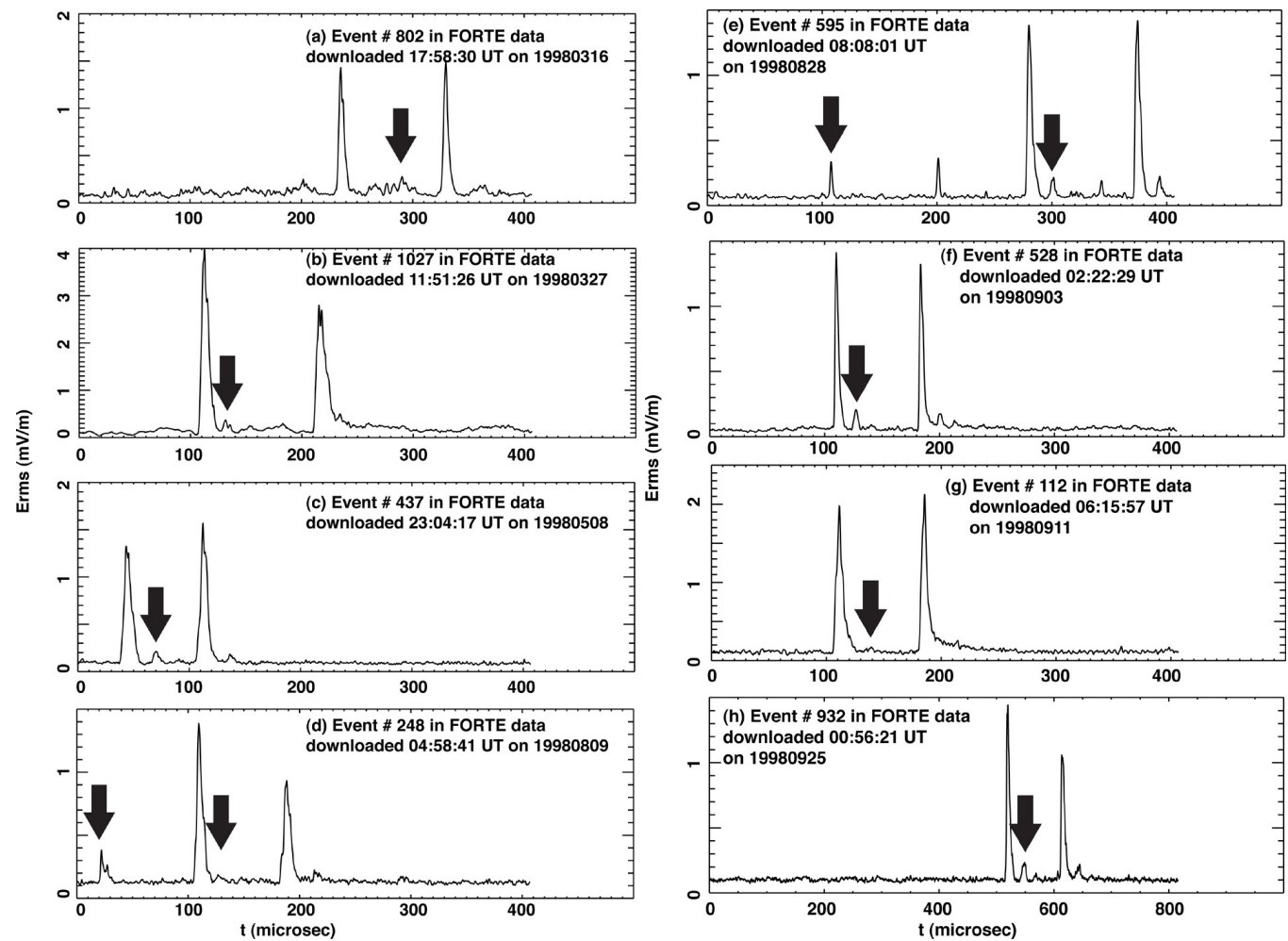

Fig. 11. Root mean square electric field vs. time, with the mean over a $1.5 \mu$ s sliding window, for each of the eight strong TIPPs in autonomously triggered TATR records that were coincident with autonomously triggered PDD. Arrows mark "secondary-breakdown pulses".

This TATR evidence is summarized as follows:

1. Strong TIPPs occuring close in time to PDD opticalirradiance triggers occur before the PDD trigger, not after.

2. Of these strong TIPPs occurring before a PDD trigger, there are eight (8) which occur with less than $0.3 \mathrm{~ms}$ separation from that trigger. Each of these eight optically correlated TIPPs displays prompt secondarybreakdown pulses, visible in the time immediately after the main pulse and before the ground-reflection echo.

3. We compare the behavior of a control group of strong TIPPs, which are tightly coincident not with optical irradiance but with NBE discharges detected by LASA in Florida, 1999. Of 26 such NBE-coincident strong TIPPs, 4 display prompt secondary-breakdown pulses, while 22 do not.

\section{Ground-based sferic-optical observations}

In 2004-2005 the Los Alamos Sferic Array (Shao et al., 2006; Smith et al., 2002; Wiens et al., 2008) was deployed across a portion of the United States Great Plains and comprised six stations recording the vertical electric field at 1 megasample $\mathrm{s}^{-1}$, traditionally called the "sferic" signal. The station placed in Oklahoma City (OUN) was also equipped with an all-sky silicon photodiode (response from 350$1100 \mathrm{~nm}$ ) whose recording was slaved to the sferic signal, with 1 megasample $\mathrm{s}^{-1}$ recording, like the sferic recording. In this manner, the sferic's relationship to optical emissions could be compared across a variety of lightning types. Preliminary results using this sensor (Nemzek et al., 2005) found very low rates of optical-NBE associations $(\sim 1 \%)$, whereas other types of lightning showed 6-20\% optical-sferic coincidence. The present study uses a larger data sample and restricts the data to events occurring within $50 \mathrm{~km}$ of the OUN station to minimize the bias of sferic detections for which the corresponding optical signal might be lost over long ranges. Although the system is capable of detecting more distant (over-the-horizon) lightning via Rayleigh scattering in the overhead air, this is not necessary in the present data selection, as almost all thunderstorms within radius $50 \mathrm{~km}$ from the OUN site were directly visible to the photodiode's all-sky field of view. We used the data from the 2005 campaign, covering May-September of that year. Events were classified using the criteria carefully developed previously (Wiens et al., 2008), so that each sferic is given variously a CG (cloud-toground), IC (intracloud), or NB (narrow bipolar) designation, plus a polarity. We discarded any detections for which an identification was indeterminate, and any whose geolocation 

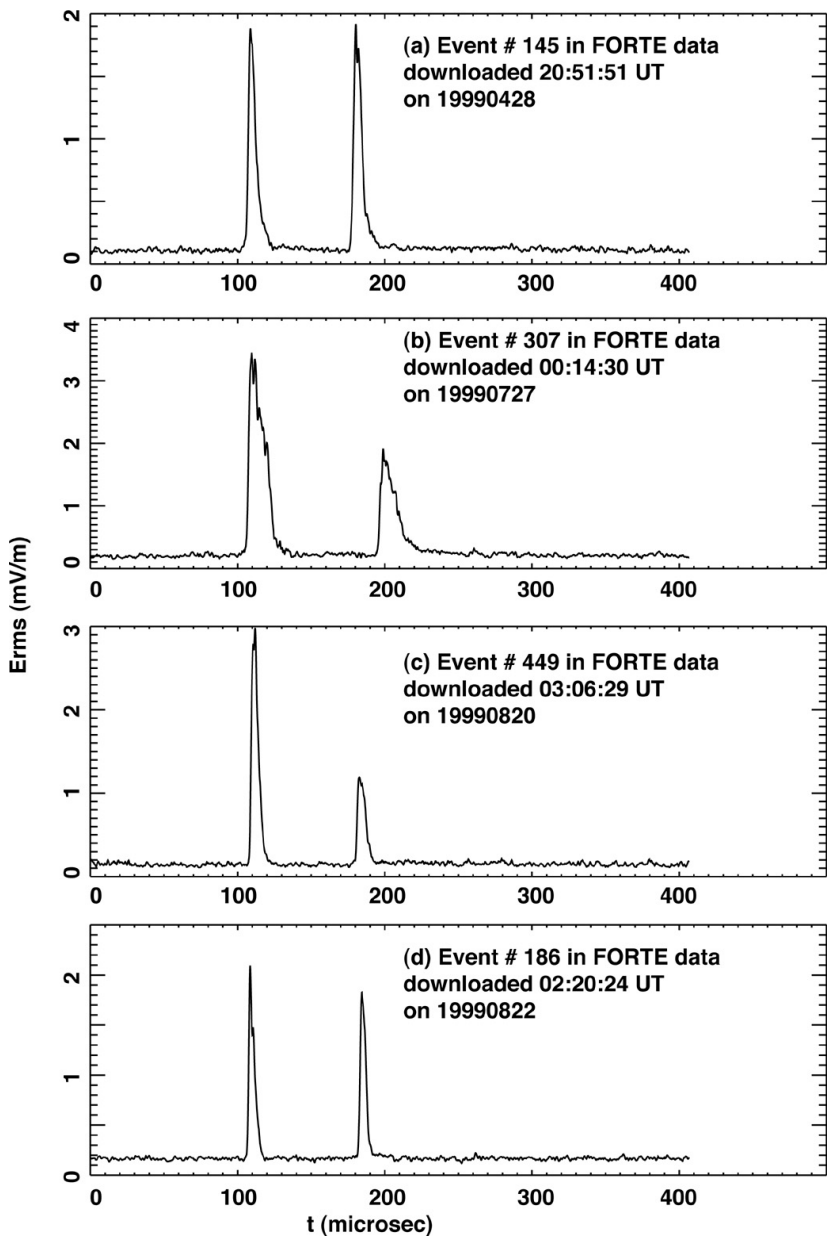

Fig. 12. Similar to Fig. 11, but for the first four strong TIPPs in autonomously triggered TATR records that were coincident with LASA-located NBE strokes.

was very poor (Wiens et al., 2008). The total number of joint sferic-optical recordings meeting these criteria is 27896.

Using these events, we created composite waveforms for each lightning type, by aligning each record's peak and averaging over events sharing that type designation. This technique effectively averages out the noise and atypical behaviors, allowing many weak, but statistically stationary, features to become evident. The resultant composite waveforms of optical power and sferic, shown in Fig. 13 and Fig. 14, are then understood to be representative of those features that persist; individual detections will of course vary from these composite averages. To make the composites, we excluded events that extended off the edge of the record; this accounts for the different numbers of events contributing to the optical and sferic composites for a given lightning type. Also, before averaging, the optical or sferic waveforms were individually re-scaled to the amplitude levels that would pertain to average distance of the data, assuming inverse-square dependence of the optical power on range, and inverse linear dependence of the sferic amplitude on range. For optical sig-

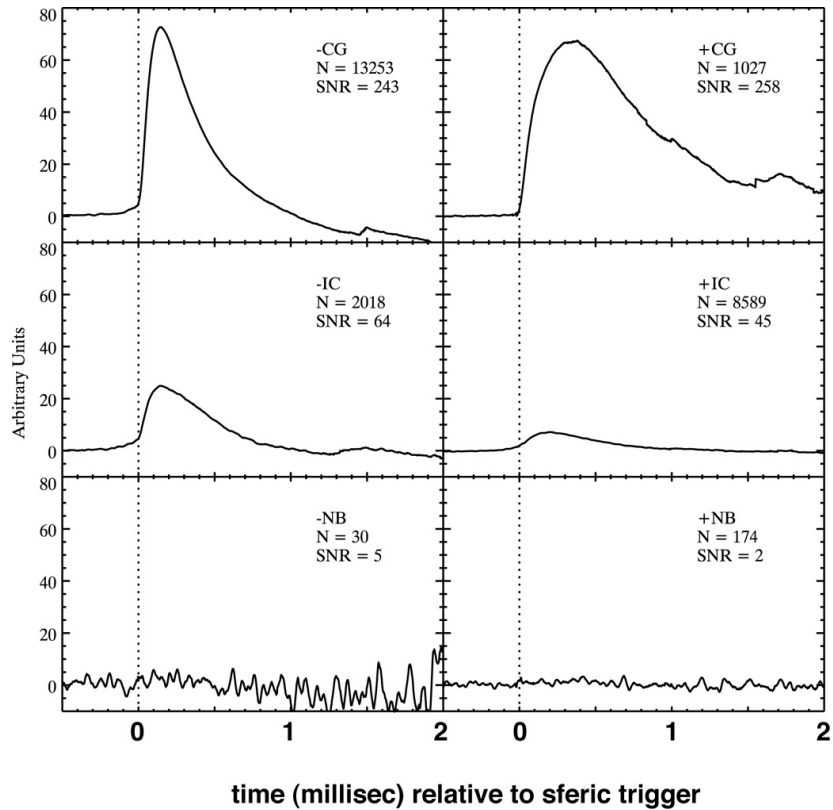

Fig. 13. Composite optical waveforms, constructed as described in the text.

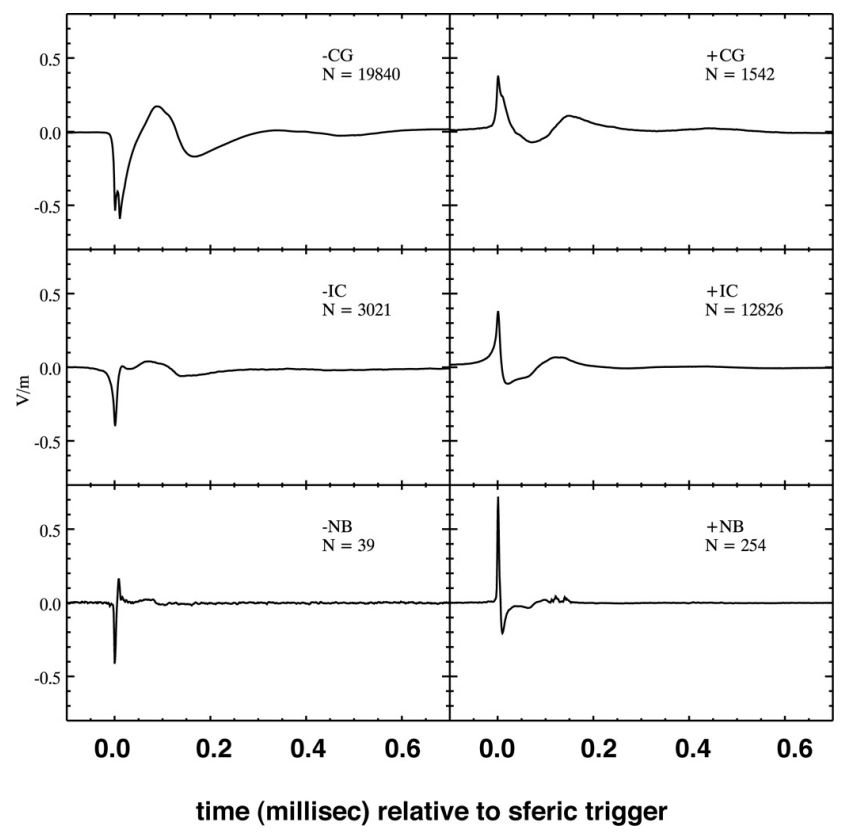

Fig. 14. Composite sferic waveforms, constructed as described in the text.

nals, the average range to event was $37 \pm 10 \mathrm{~km}$, while for sferic signals the average range to event was $428 \pm 28 \mathrm{~km}$, where the spread is between different categories. (We used the sferic signal recorded by the second most distant station, to avoid signals with near-field effects present. Thus although OUN is the nearest station, and the only station recording optical, it is not the preferred station for the sferic waveform 


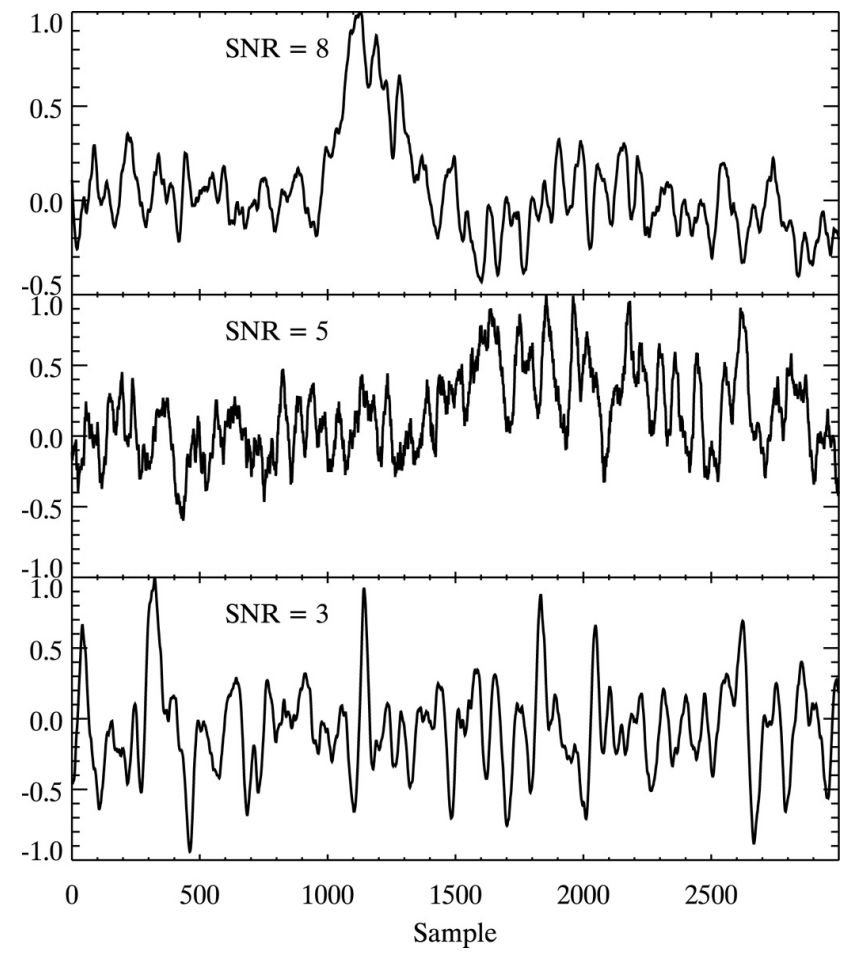

Fig. 15. Examples of normalized optical signals with varying SNR, showing that anything with $\mathrm{SNR} \sim 5$ is a reasonable threshold below which we regard the optical recording as a non-detection.

recording, because it is likely to be contaminated by electrostatic and inductive effects. We seek only the radiation, far-field sferic waveform.)

Figure 13 shows composite average curves of optical power, while Fig. 14 shows composite average curves of the sferic waveform. In each figure the negative polarity is in the left column, while the positive is in the right column. CG events are in the top row, IC events are in the middle row, and NBE events are in the bottom row. The composite curves in Figs. 13 and 14 vary among the different lightning types and are remarkably smooth, indicating that the technique works quite well at creating a statistical waveform shape for both optical power and sferic waveform. The ordinate scale in Fig. 13, although uncalibrated, is the same for all six categories, so that average optical power may be directly compared between the categories. The most obvious feature of the optical composites is the lack of optical emission from sferic NB events. Although there are far fewer NBE waveforms with which to average away the background noise level, we can nevertheless say that any optical emission from those events is at least a factor of 10 weaker than that from the weakest IC lightning and 100 times weaker than that from CGs. Also evident is the fact that the optical emission from a positive polarity ground stroke persists much longer than that from a negative polarity event, even though the sferic signal itself is not particularly longer for
Table 5. Ground-based sferic-optical data sample.

\begin{tabular}{ccc}
\hline $\begin{array}{c}\text { Lightning } \\
\text { type }\end{array}$ & $\begin{array}{c}\text { \# Sferic events within } \\
50 \mathrm{~km} \text { of OUN station }\end{array}$ & $\begin{array}{c}\text {... with detectable } \\
\text { optical counterpart }\end{array}$ \\
\hline$+\mathrm{CG}$ & 998 & $347(35 \%)$ \\
- CG & 14429 & $7844(54 \%)$ \\
$+\mathrm{IC}$ & 10145 & $2789(27 \%)$ \\
$-\mathrm{IC}$ & 2115 & $849(40 \%)$ \\
$+\mathrm{NB}$ & 193 & $2(1 \%)$ \\
$-\mathrm{NB}$ & 24 & 0 \\
\hline
\end{tabular}

$+\mathrm{CG}$ than for -CG. We estimate the optical signal-to-noise ratio (SNR) of any statistical feature in the optical composite curves, by taking the ratio of the peak value to the root mean square noise fluctuations. The composite-curve's estimated SNR is noted in the legend of each plot in Fig. 13.

The sferic composite waveforms in Fig. 14 are statistically reliable mainly in the initial feature, due to direct "ground wave" propagation to the recording station. Later features are due in part to ionospheric reflections (Jacobson et al., 2012; Shao and Jacobson, 2009; Shao et al., 2012; Smith et al., 1999a; Wiens et al., 2008) and thus are partly washed-out in the statistical average over individually varying ranges and azimuths (Jacobson et al., 2012; Shao and Jacobson, 2009; Shao et al., 2012).

We now delve into recordings of individual events. Figure 15 compares three individual (not composited) optical records with different values of individual SNR to show that SNR $>5$ is a reasonable threshold, below which we can assume no optical emission was detected. The baseline ("DC") value has been subtracted, so the fluctuations can attain negative values in this display. The sample step is $1 \mu \mathrm{s}$. The ordinate is separately normalized for each individual event. We used this threshold of SNR $>5$ to find optical coincidences for all lightning types other than NB, because there are too many events to examine individually. For NB events, because there are so few events, we visually inspected the sfericoptical signals for each event, to find any events with evidence of optical emission. We arrive at the statistics shown in Table 5.

We now discuss the positive polarity NBs, of which 193 events were recorded. We find that two positive NB events apparently show optical emission. These are shown in Fig. 16, and there truly do appear to be +NB sferic events with associated optical emission. Perhaps the key detail of these two events is that the NB main sferic pulse is preceded by earlier sferic activity in the record, indicating that the NB sferic is not the only activity. Thus, it is reasonable to assume that the optical signal is equally as likely to be related to the additional sferic activity as to be related to the NB sferic itself. For comparison, Fig. 17 shows two other sfericoptical pairs for $+\mathrm{NB}$ events, of similar sferic strength to those shown in Fig. 16, for which there is not even a hint 

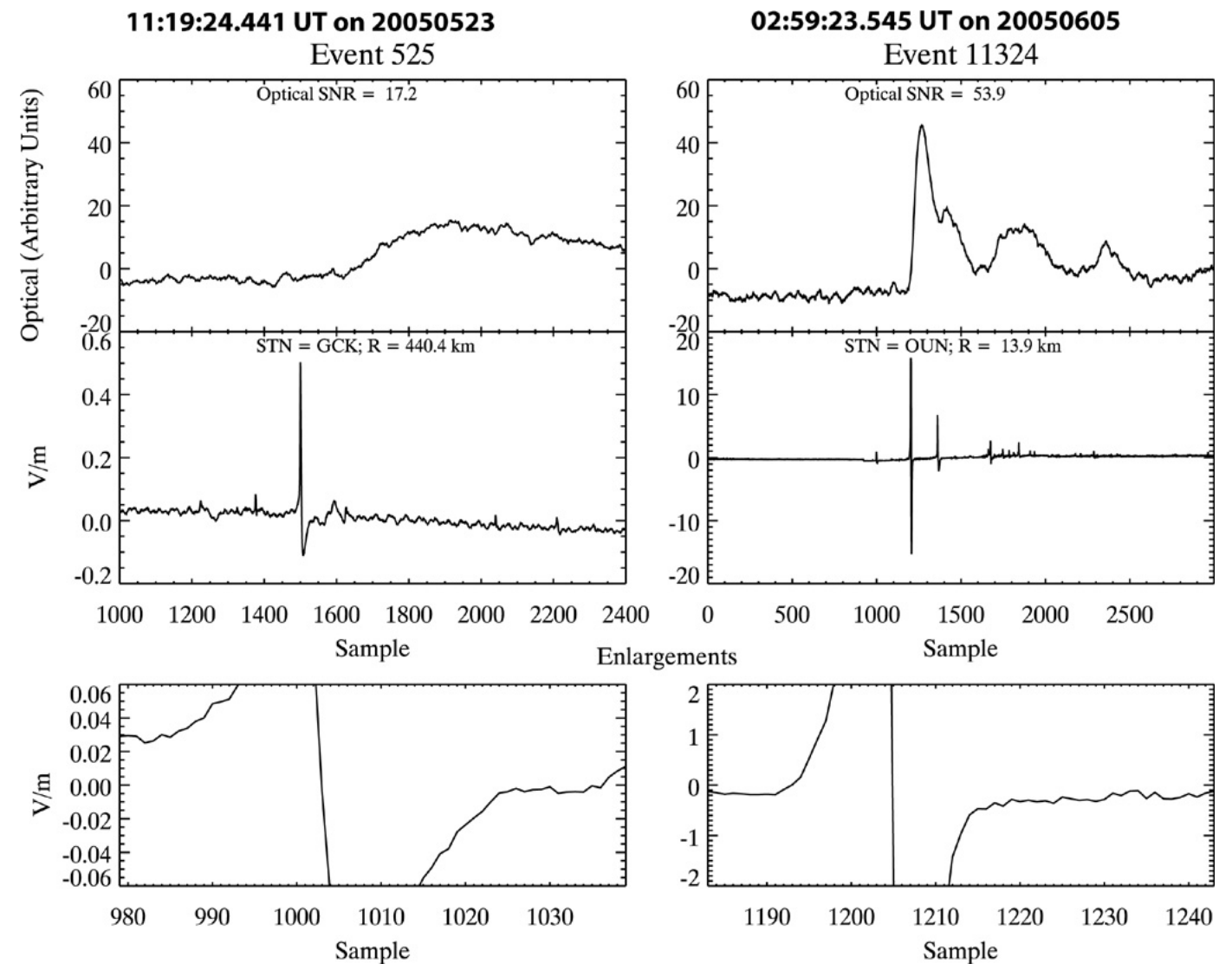

Fig. 16. The two $+\mathrm{NB}$ events that appear to show optical emission. The top panels are the optical recordings coincident with the sferic triggers. The middle panels are the sferic recordings themselves. The bottom panels are closeups in both ordinate and abscissa on the main NBE pulse, showing slow rise-times ( $>10 \mu \mathrm{s}$ ). Note that for one event we show the sferic data from the closest station (in Oklahoma City) to the optical sensor. The reason is that we wish to highlight the additional radio disturbances prior to the main NB pulse. For both event 525 and event 11324, there are significant sferic features starting before both the main NB pulse and that pulse's ionospheric reflections.

of optical emission. The bottom panels of Figs. 16 and 17 show zoom views of $60 \mu$ s on the abscissa and clipped ordinate scales about the sferic peak for each event. The only obvious difference between those two NB events that created optical emission in Fig. 16 and those in Fig. 17 that did not lies in the rapidity of the sferic signal onset. The dark NBEs in Fig. 17 rise from background to peak in less than $5 \mu$, whereas the apparently "luminous" NBs have, by comparison, a long, slow rise in sferic emission on the order of 10$20 \mu$ s. The paucity of cases (only two) in which NB sferics had any optical counterpart makes it impossible, however, to state whether the rise-time is a robust discriminant between "dark" and "luminous" NB events. At any rate, the two "luminous" NB events in Fig. 16 are also distinguished by the presence of additional discharge signals preceding the main NB pulse.

Overall, it appears as if the negative polarity NBEs are devoid of measurable coincident optical emission, even in the present case where the optical sensor is within no more than $50 \mathrm{~km}$ of the lightning event. As always, the key qualifier is the word "measurable", meaning that it is possible that subthreshold optical emission occurs in these events.

\section{Conclusions}

We have examined in detail the coincidence and timing relationship between, on the one hand, the most radio-powerful intracloud lightning events and, on the other hand, optical outputs of the same discharge process. We have done this, first, using coordinated VHF and optical observations from the FORTE satellite and, second, using coordinated sferic and all-sky optical observations from the Los Alamos Sferic Array. In either case, we find that the sought coincidences are exceedingly rare. Moreover, in the handful of coincidences between optical and intense radio emissions that have been identified, the radio emissions differ from their usual behavior, by being accompanied by approximately simultaneous "conventional" lightning radio emissions.

It is possible that the coincident detections of light are therefore associated with atypical additional radio signals 
08:42:13.806 UT on 20050914

Event 41495
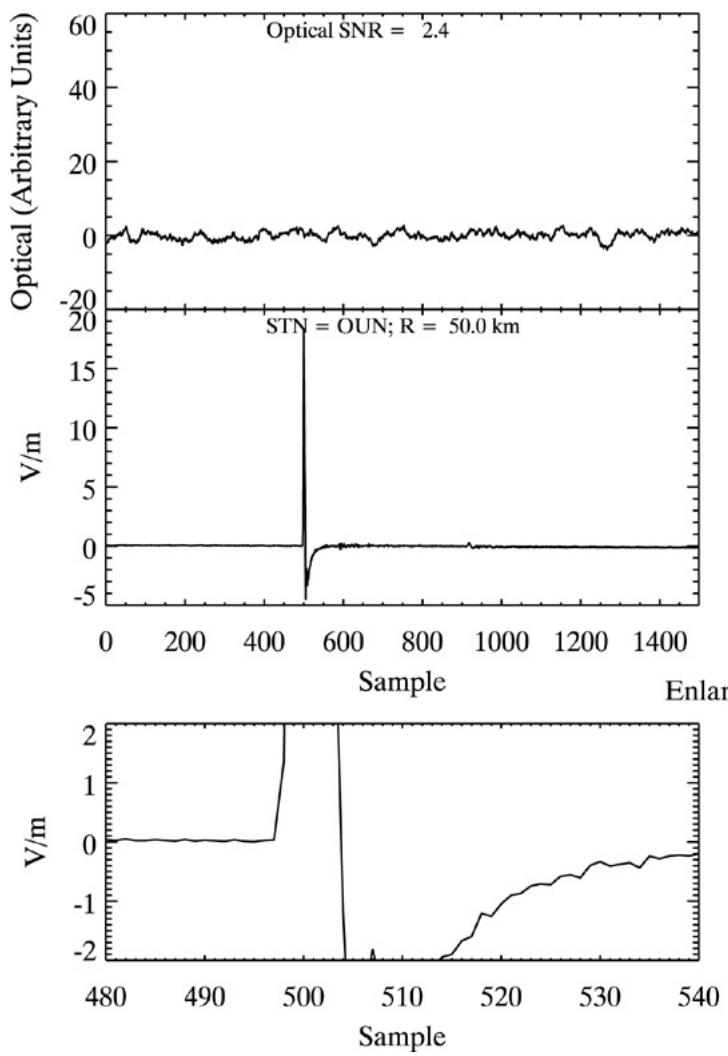

09:24:03.192428 UT on 20050914

Event 42124
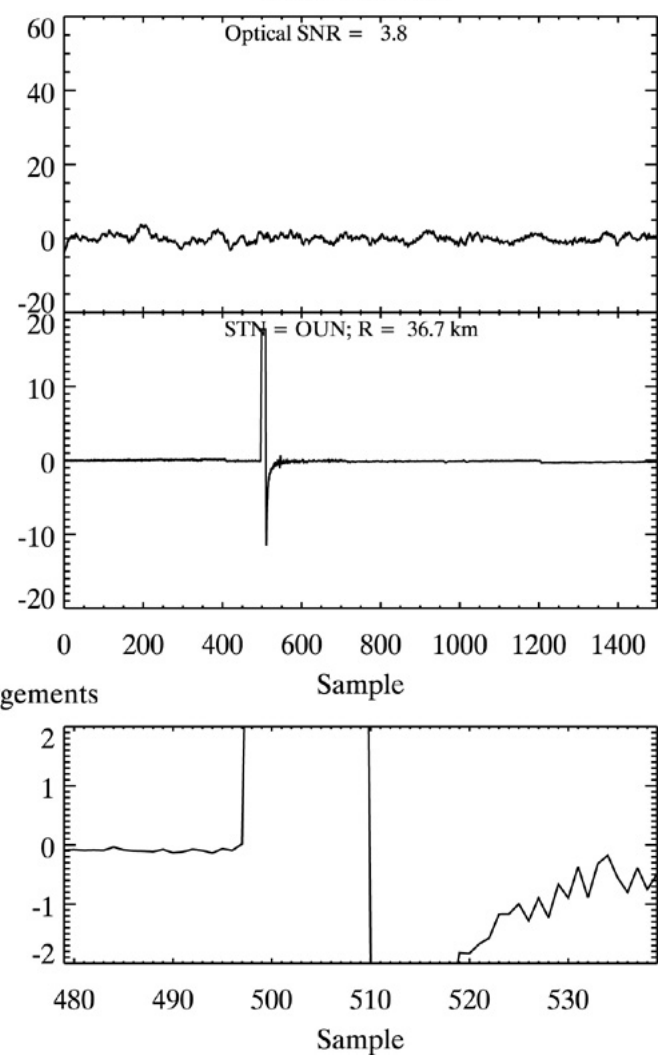

Fig. 17. Two + NB events of similar sferic intensity to those shown in Fig. 16, but which do not show optical emission. The panels are laid out as in Fig. 16 for direct comparison. Note that for both events we show the sferic data from the closest station (in Oklahoma City) to the optical sensor. The reason is that we wish to highlight any possible additional radio disturbances prior to the main NB pulse. However, we still find a complete absence of additional radio disturbances. The bottom panel close-up shows that these events rise more rapidly from background levels to their peaks (rise-time $<5 \mu \mathrm{s}$ ), in contrast to the events shown in Fig. 16.

appearing before, during, or shortly after the intense radio emissions. Thus, the most radio-powerful intracloud emissions continue to appear light-deficient compared to ordinary lightning processes. As such, these intense intracloud radio emissions appear to share with terrestrial gamma flashes the unusual status of differing essentially from radio emissions of ordinary incandescent, thermalized lightning discharges (Connaughton et al., 2013). This does not imply that the two phenomena are produced in a like manner, but only that the current in each phenomenon appears to be carried by energetic electrons not in thermal equilibrium with the neutral gas. It appears that to make substantial progress on understanding the most radio-powerful intracloud emissions it will be necessary to record fast $E$-field changes near the event itself with in situ three-axis probes, such as was recently done with a balloon-borne payload with outstanding effect for an ordinary intracloud flash (Winn et al., 2011). If in situ payloads can be flown enough times through thunderclouds, it will be only a matter of time before the "compact intracloud discharge" is observed in closer proximity.
Acknowledgements. One author (ARJ) was supported in this work by National Science Foundation grant 0947130 and by the Defense Advanced Research Projects Agency's Nimbus program, led by Dr. Matthew Goodman. The other authors contributed under the auspices of the US Department of Energy.

Topical Editor K. Hosokawa thanks two anonymous referees for their help in evaluating this paper.

\section{References}

Boccippio, D. J., Driscoll, K., Koshak, W., Blakeslee, R., Boeck, W., Buechler, D., Christian, H., and Goodman, S.: The Optical Transient Detector (OTD): Instrument characteristics and crosssensor validation, J. Atmos. Oceanic Tech., 17, 441-458, 2000.

Boccippio, D. J., Cummins, K. L., Christian, H. J., and Goodman, S. J.: Combined satellite- and surface-based estimation of the intracloud-cloud-to-ground lightning ratio over the Continental United States, Mon. Weather Rev., 129, 108-122, 2001.

Christian, H. J., Blakeslee, R. J., and Goodman, S. J.: The detection of lightning from geostationary orbit, J. Geophys. Res., 94, 13329-13337, 1989. 
Christian, H. J., Blakeslee, R. J., Goodman, S. J., Mach, D. A., Stewart, M. F., Buechler, D. E., Koshak, W. J., Hall, J. M., Boeck, W. L., Driscoll, K. T., and Boccippio, D. J.: The Lightning Imaging Sensor, paper presented at 11 th International Conference on Atmospheric Electricity, NASA, Global Hydrology and Climate Center, NASA Marshall Space Flight Center, Huntsville, Alabama, 1999.

Christian, H. J., Blakeslee, R. J., Boccippio, D. J., Boeck, W. L., Buechler, D. E., Driscoll, K. T., Goodman, S. J., Hall, J. M., Koshak, W. J., Mach, D. M., and Stewart, M. F.: Global frequency and distribution of lightning as observed from space by the Optical Transient Detector, J. Geophys. Res., 108, 4005, doi:4010.1029/2002JD002347, 2003.

Connaughton, V., Briggs, M. S., Xiong, S., Dwyer, J. R., Hutchins, M. L., Grove, J. E., Chekhtman, A., Tierney, D., Fitzpatrick, G., Foley, S., McBreen, S., Bhat, P. N., Chaplin, V. L., Cramer, E., Fishman, G. J., Holzworth, R. H., Gibby, M., von Kienlin, A., Meegan, C. A., Paciesas, W. S., Preece, R. D., and Willson-Hodge, C.: Radio signals from electron beams in Terrestrial Gamma Flashes, J. Geophys. Res., accepted, doi:10.1002/jgra.50205, 2013.

Cummins, K. L. and Murphy, M. J.: An overview of lightning location systems: History, techniques, and data uses, with an in-depth look at the U. S. NLDN, IEEE Trans. Electromagnetic Compatibility, 51, 499-518, 2009.

Cummins, K. L., Murphy, M. J., Bardo, E. A., Hiscox, W. L., Pyle, R., and Pifer, A. E.: Combined TOA/MDF technology upgrade of U. S. National Lightning Detection Network, J. Geophys. Res., 103, 9035-9044, 1998.

Eack, K. B.: Electrical characteristics of narrow bipolar events, Geophys. Res. Lett., 31, L20102, doi:20110.21029/22004GL021117, 2004.

Gallimberti, I., Bacchiega, G., Bondiou-Clergerie, A., and Lalande, P.: Fundamental processes in long air gap discharges, C. R. Physique, 3, 1335-1359, 2002.

Hamlin, T., Light, T. E., Shao, X. M., Eack, K. B., and Harlin, J. D.: Estimating lightning channel characteristics of positive narrow bipolar events using intrachannel current reflection signatures, J. Geophys. Res., 112, D14108, doi:14110.11029/12007JD008471, 2007.

Holden, D. N., Munson, C. P., and Devenport, J. C.: Satellite observations of transionospheric pulse pairs, Geophys. Res. Lett., 22, 889-892, 1995.

Jacobson, A. R.: How do the strongest radio pulses from thunderstorms relate to lightning flashes?, J. Geophys. Res., 108, 4778, doi:4710.1029/2003JD003936, 2003a.

Jacobson, A. R.: Relationship of intracloud-lightning radiofrequency power to lightning-storm height, as observed by the FORTE satellite, J. Geophys. Res., 108, 4204, doi:10.1029/2002JD002956, 2003b.

Jacobson, A. R. and Heavner, M. J.: Comparison of Narrow Bipolar Events with ordinary lightning as proxies for severe convection, Mon. Weather Rev., 133, 1144-1154, 2005.

Jacobson, A. R. and Light, T. E. L.: Bimodal radiofrequency pulse distribution of intracloud-lightning signals recorded by the FORTE satellite, J. Geophys. Res., 108, 4266, doi:4210.1029/2002JD002613, 2003.

Jacobson, A. R. and Light, T. E. L.: Revisiting "Narrow Bipolar Event" intracloud lightning using the FORTE satellite, Ann.
Geophys., 30, 389-404, doi:10.5194/angeo-30-389-2012, 2012. Jacobson, A. R. and Shao, X.-M.: On-orbit direction-finding of lightning radio-frequency emissions recorded by the FORTE satellite, Radio Sci., 37, doi:10.1029/2001RS002510, 2002.

Jacobson, A. R., Knox, S. O., Franz, R., and Enemark, D. C.: FORTE observations of lightning radio-frequency signatures: Capabilities and basic results, Radio Sci., 34, 337-354, 1999.

Jacobson, A. R., Cummins, K. L., Carter, M., Klingner, P., RousselDupré, D., and Knox, S. O.: FORTE radio-frequency observations of lightning strokes detected by the National Lightning Detection Network, J. Geophys. Res., 105, 15653-15662, 2000.

Jacobson, A. R., Boeck, W., and Jeffery, C.: Comparison of Narrow Bipolar Events with ordinary lightning as proxies for the microwave-radiometry ice-scattering signature, Mon. Weather Rev., 135, 1354-1363, 2007.

Jacobson, A. R., Holzworth, R. H., and Shao, X.-M.: Observations of multi-microsecond VHF pulsetrains in energetic intracloud lightning discharges, Ann. Geophys., 29, 1587-1604, doi:10.5194/angeo-29-1587-2011, 2011.

Jacobson, A. R., Shao, X.-M., and Lay, E.: Time-domain waveform, and azimuth variation, of ionospherically reflected VLF/LF radio emissions from lightning, Radio Sci., 47, RS4001, doi:4010.1029/2012RS004980, 2012.

Kirkland, M. W., Suszcynsky, D. M., Guillen, J. L. L., and Green, J. L.: Optical observations of terrestrial lightning by the FORTE satellite photodiode detector, J. Geophys. Res., 106, 3349933509, 2001

Koshak, W. J., Solakiewicz, R. J., Phanord, D. D., and Blakeslee, R. J.: Diffusion model for lightning radiative transfer, J. Geophys. Res., 99, 14361-14371, 1994.

Le Vine, D. M.: Sources of the strongest rf radiation from lightning, J. Geophys. Res., 85, 4091-4095, 1980.

Light, T. and Hamlin, T.: Coordinated Optical/VLF Lightning Observations, Eos Trans. AGU, 89, 53 Fall Meeting Supplement, AE11A-0293, 2008.

Light, T. E. L. and Jacobson, A. R.: Characteristics of impulsive VHF lightning signals observed by the FORTE satellite, J. Geophys. Res., 107, 4756, doi:10.1029/2001JD001585, 2002.

Light, T. E., Suszcynsky, D. M., and Jacobson, A. R.: Coincident Radio Frequency and Optical Emissions from Lightning, Observed with the FORTE Satellite, J. Geophys. Res., 106, 28223 28231, 2001a.

Light, T. E., Suszcynsky, D. M., Kirkland, M. W., and Jacobson, A. R.: Simulations of lightning optical waveforms as seen through clouds by satellites, J. Geophys. Res., 106, 17103-17111, 2001 b.

Massey, R. S. and Holden, D. N.: Phenomenology of transionospheric pulse pairs, Radio Sci., 30, 1645-1659, 1995.

Massey, R. S., Holden, D. N., and Shao, X.-M.: Phenomenology of trans-ionospheric pulse pairs: Further observations, Radio Sci., 33, 1755-1761, 1998.

Nag, A. and Rakov, V. A.: Electromagnetic pulses produced by bouncing-wave-type lightning discharges, IEEE Trans. Electromagnetic Compatibility, 51, 466-470, 2009.

Nag, A. and Rakov, V. A.: Compact intracloud lightning discharges: 2. Estimation of electrical parameters, J. Geophys. Res., 115, D20103, doi:10.1029/2010JD014237, 2010a.

Nag, A. and Rakov, V. A.: Compact intracloud lightning discharges: 1. Mechanism of electromagnetic radiation and modeling, J. Geophys. Res., 115, D20102, doi:10.1029/2010JD014235, 
2010b.

Nag, A., Rakov, V. A., Tsalikis, D., and Cramer, J. A.: On phenomenology of compact intracloud lightning discharges, J. Geophys. Res., 115, D14115, doi:14110.11029/12009JD012957, 2010.

Nemzek, R. J., Light, T. E., and Suszcynsky, D. M.: A Search for Optical Emissions from Narrow Bipolar Events, Eos Trans. AGU, Fall Mtg. Suppl., abstract AE41A-0140, 2005.

Rison, W., Thomas, R. J., Krehbiel, P. R., Hamlin, T., and Harlin, J.: A GPS-based three-dimensional lightning mapping system: Initial observations in central New Mexico, Geophys. Res. Lett., 26, 3573-3576, 1999.

Shao, X.-M. and Jacobson, A. R.: Polarization observations of broadband VHF signals by the FORTE satellite, Radio Sci., 36, 1573-1589, 2001.

Shao, X.-M. and Jacobson, A. R.: Model simulation of Very-LowFrequency and Low-Frequency lightning signal propagation over intermediate ranges, IEEE Trans. Electromag. Compat., 51, 519$525,2009$.

Shao, X. M. and Krehbiel, P. R.: The spatial and temporal development of intracloud lightning, J. Geophys. Res., 101, 2664126668, 1996.

Shao, X.-M., Stanley, M., Regan, A., Harlin, J., Pongratz, M., and Stock, M.: Total lightning observations with the new and improved Los Alamos Sferic Array (LASA), J. Atmos. Oceanic Technol., 23, 1273-1288, 2006.

Shao, X.-M., Lay, E., and Jacobson, A. R.: On the behavior of return stroke current and the remotely detected electric field change waveform, J. Geophys. Res., 117, D07105, doi:10.1029/2011JD017210, 2012.

Smith, D. A., Argo, P. E., Eack, K. B., Holden, D. N., Massey, R. S., Shao, X. M., Wiens, K. C., and Krehbiel, P. R.: Observations and inferred physical characteristics of compact intracloud discharges, in Proceedings of the 11th International Conference on Atmospheric Electricity, paper presented at 11th International Conference on Atmospheric Electricity, International Commission on Atmospheric Electricity, Global Hydrology and Climate Center, NASA Marshall Space Flight Center, Huntsville, Alabama, 1999a.

Smith, D. A., Shao, X. M., Holden, D. N., Rhodes, C. T., Brook, M., Krehbiel, P. R., Stanley, M., Rison, W., and Thomas, R. J.: A distinct class of isolated intracloud lightning discharges and their associated radio emissions, J. Geophys. Res., 104, 4189-4212, 1999b.
Smith, D. A., Eack, K. B., Harlin, J., Heavner, M. J., Jacobson, A. R., Massey, R. S., Shao, X. M., and Wiens, K. C.: The Los Alamos Sferic Array: A research tool for lightning investigations, J. Geophys. Res., 107, doi:10.1029/2001JD000502, 2002.

Smith, D. A., Heavner, M. J., Jacobson, A. R., Shao, X. M., Massey, R. S., Sheldon, R. J., and Wiens, K. C.: A method for determining intracloud lightning and ionospheric heights from VLF/LF electric field records, Radio Sci., 39, RS1010, doi:10.1029/2002RS002790, 2004.

Suszcynsky, D. M., Kirkland, M. W., Jacobson, A. R., Franz, R. C., Knox, S. O., Guillen, J. L. L., and Green, J. L.: FORTE observations of simultaneous VHF and optical emissions from lightning: Basic Phenomenology, J. Geophys. Res., 105, 2191-2201, 2000.

Suszcynsky, D. M., Light, T. E., Davis, S., Kirkland, M. W., Green, J. L., and Guillen, J.: Coordinated Observations of Optical Lightning from Space using the FORTE Photodiode Detector and CCD Imager, J. Geophys. Res., 106, 17897-17906, 2001.

Thomas, R. J., Krehbiel, P. R., Rison, W., Hamlin, T., Harlin, J., and Shown, D.: Observations of VHF source powers radiated by lightning, Geophys. Res. Lett., 28, 143-146, 2001.

Tierney, H. E., Jacobson, A. R., Roussel-Dupré, R., and Beasley, W. H.: Transionospheric pulse pairs originating in maritime, continental, and coastal thunderstorms: Pulse energy ratios, Radio Sci., 37, doi:10.1029/2001RS002506, 2002.

Watson, S. S. and Marshall, T. C.: Current propagation model for a narrow bipolar pulse, Geophys. Res. Lett., 34, L04816, doi:10.1029/2006GL027426, 2007.

Wiens, K. C., Hamlin, T. D., Harlin, J., and Suszcynsky, D.: Relationships among Narrow Bipolar Events, "total" lightning, and radar-inferred convective strength in Great Plains Thunderstorms, J. Geophys. Res., 113, D05201, doi:10.1029/2007JD009400, 2008.

Winn, W. P., Aulich, G. D., Hunyady, S. J., Eack, K. B., Edens, H. E., Krehbiel, P. R., Rison, W., and Sonnenfeld, R. G.: Lightning leader stepping, $\mathrm{K}$ changes, and other observations near an intracloud flash, J. Geophys. Res., 116, D23115, doi:10.1029/2011JD015998, 2011.

Wu, T., Dong, W., Zhang, Y., and Wang, T.: Comparison of positive and negative compact intracloud discharges, J. Geophys. Res., 116, D03111, doi:10.1029/2011JD017054, 2011.

Wu, T., Dong, W., Zhang, Y., Funaki, T., Yoshida, S., Morimoto, T., Ushio, T., and Kawasaki, Z.: Discharge height of lightning narrow bipolar discharges, J. Geophys. Res., 117, D05119, doi:10.1029/2011JD017054, 2012. 